\title{
Skeletal Muscle Calpain Acts through Nitric Oxide and Neural miRNAs to Regulate Acetylcholine Release in Motor Nerve Terminals
}

\author{
Haipeng Zhu, ${ }^{1 \star}$ Bula J. Bhattacharyya, ${ }^{2 *}$ Hong Lin, ${ }^{3}$ and Christopher M. Gomez ${ }^{1}$ \\ ${ }^{1}$ Department of Neurology, University of Chicago Medical Center, Chicago, Illinois 60637, ${ }^{2}$ Department of Molecular Pharmacology and Biological \\ Chemistry, Feinberg School of Medicine, Northwestern University, Chicago, Illinois 60611, and '3Departments of Neurology and Pediatrics, the Children's \\ Hospital of Philadelphia, Philadelphia, Pennsylvania 19104-4318
}

Cholinergic overactivity in diseases of neuromuscular transmission elicits a retrograde signal resembling homeostatic synaptic plasticity that downregulates transmitter release. Understanding this compensatory pathway could provide insights into novel therapeutic avenues and molecular mechanisms underlying learning and memory. Here we identify nitric oxide as a possible source of this signal in pathological human and mouse muscle samples and link this signaling pathway to changes in synaptic function in the neuromuscular junction. We further show that neuronal nitric oxide synthase is regulated by cholinergic excess through activation of skeletal muscle calpain and its effect on Cdk5 and CaMKII, leading to direct modulation of presynaptic function. Finally, we show that this signaling pathway acts through specific miRNA control of presynaptic vesicle protein expression. The control of presynaptic miRNA levels by postsynaptic activity represents a novel mechanism for the modulation of synaptic activity in normal or pathological conditions.

\section{Introduction}

Different forms of synaptic plasticity have been suggested to underlie learning and memory as well as synaptic alterations in neurological diseases such as epilepsy, Alzheimer's disease, and dystonia (Ben-Ari, 2008; Palop and Mucke, 2010; Quartarone and Pisani, 2011). However, the direct evidence of synaptic plasticity in human neurological disease remains largely unknown. Characterization of the primary synaptic defects in several genetic neuromuscular diseases revealed functional and structural abnormalities in both presynaptic and postsynaptic sites of the neuromuscular junction (NMJ). In congenital endplate acetylcholinesterase deficiency (CEAD) due to loss-of-function mutations in the collagen-like tail subunit of endplate AChE (ColQ) that anchors AChE to the postsynaptic membrane, the abnormalities at the NMJ include small nerve terminals, reduced acetylcholine release, and postsynaptic degeneration (Engel et al., 1977; Ohno et al., 1998). The postsynaptic degenerative changes were attributed to excitotoxic damage from $\mathrm{Ca}^{2+}$ overload of the postsynaptic region resulting from excessive ACh activation of the muscle nicotinic ACh receptor

Received Jan. 15, 2013; revised; ; accepted March 7, 2013.

Author contributions: H.Z., H.L., and C.M.G. designed research; H.Z. and B.J.B. performed research; C.M.G. contributed unpublished reagents/analytic tools; H.Z., B.J.B., H.L., and C.M.G. analyzed data; H.Z., B.J.B., and C.M.G. wrote the paper.

This work was supported by the National Institutes of Health (Grant \#R01 NS33202 to C.M.G.). We thank Dr. Andrew G. Engel, Dr. Ricardo Maselli, and Dr. Rosana Scola for providing SCS and CEAD patient muscle samples and Dr. Engel and Dr. Maselli for helpful comments on the manuscript.

The authors declare no competing financial interests.

*H.Z. and B.J.B. contributed equally to this work.

Correspondence should be addressed to Dr. Christopher M. Gomez, Department of Neurology, AMB S237, MC2030, University of Chicago Medical Center, 5841 S. Maryland, Chicago, IL 60637. E-mail: gomez001@uchicago.edu.

D01:10.1523/JNEUROSCI.0224-13.2013

Copyright $\odot 2013$ the authors $\quad 0270-6474 / 13 / 337308-17 \$ 15.00 / 0$
(AChR). The presynaptic changes in CEAD, however, were mysterious and explained as a possible "compensatory response" to the effect of excessive cholinergic activation (Engel et al., 2010). Similar changes in the nerve terminus have been seen in pharmacological models of cholinesterase inhibition (Roberts and Thesleff, 1969; Tiedt et al., 1978), and in genetic AChE knock-out (KO) models (Adler et al., 2011).

Slow-channel congenital myasthenic syndrome (SCS) due to mutations in the muscle AChR shows similar postsynaptic defects and presynaptic abnormalities to $\mathrm{CEAD}$, attributed to prolonged openings of the AChR channel and $\mathrm{Ca}^{2+}$ overload at the subsynaptic region (Engel et al., 1982; Engel et al., 1996; Gomez et al., 1996). We have generated a series of SCS transgenic mouse lines (mSCS) that develop similar disease process with respect to impairment of both postsynaptic and presynaptic components (Groshong et al., 2007; Zhu et al., 2011). The presynaptic changes in these postsynaptic disorders strongly suggest that a compensatory response reduces synaptic strength via a retrograde signal resembling homeostatic synaptic plasticity. Our previous studies demonstrated that overexpression of human calpastatin (CPST), the natural inhibitor of calpain, significantly improved strength and neuromuscular transmission in mSCS (Groshong et al., 2007) and strongly suggested that postsynaptic calpain activity negatively regulates a retrograde signal that influences presynaptic nerve function.

In this study, we show that presynaptic alterations in quantal release at the normal and pathological NMJ are dependent on a calpain-activated neuronal nitric oxide synthase (nNOS) pathway. nNOS activity is abnormally increased at the NMJ in SCS mice and in muscle biopsies from patients with SCS or CEAD. Reducing nNOS activity via inhibition of calpain or Cdk5 or via 
chemical inhibitor improves presynaptic strength in wild-type (WT) and mSCS muscles, demonstrating that calpain acts via nNOS activity to modulate quantal release. Furthermore, presynaptic alterations in quantal release are correlated with miR-124and miR-142-regulated Rab3a expression in motor nerve. Our findings reveal a novel pathway for retrograde control of presynaptic function in the NMJ that may underlie homeostatic synaptic plasticity and provide the basis for impaired synaptic function and potential therapeutic strategy for neuromuscular disorders.

\section{Materials and Methods}

Materials. Chemical reagents were from Sigma. Cell culture materials were from Invitrogen. Fluorescence-tagged secondary antibody was from Life Technologies. Secondary antibodies with horseradish peroxidase were from GE Healthcare Bioscience. Primary antibodies to the following targets were used: p35/25 (1:1000; Cell Signaling Technology), CaMKII (1:1000; Abcam), p-CaMKII (Thr286; 1:500; Cell Signaling Technology), Cdk5 (1:500; SCBT), CPST (1:500; SCBT), nNOS (1:1000; Abcam), phospho-nNOS ser847 (1:500; Abcam), phospho-nNOS ser1412 (1:500; Abcam), cGMP (1:100; Abcam), Ras-related protein Rab-3a (Rab3a, 1:500; SCBT), Synaptic Vesicle Glycoprotein 2A (SV2a, 1:500; SCBT), and glyceraldehyde 3-phosphate dehydrogenase (GAPDH; 1:5000; Ambion).

Plasmids and construction. Full-length human CPST (kind gift from Dr. Masatoshi Maki, Nagoya University, Nagoya, Japan) was inserted into pcDNA3 plasmid. CaMKII-GFP plasmid was a kind gift from Dr. Tobias Meyer, Stanford University, Stanford, CA. nNOS plasmid was a kind gift from Dr. E. Clementi, San Raffaele Scientific Institute, Milan, Italy. CDK5DN plasmid (D144N; K33T) was a kind gift from Dr. Nancy Y. Ip, Biotechnology Research Institute and Molecular Neuroscience Center, Hong Kong University of Science and Technology, Hong Kong, China (Fu et al., 2007). Cdk5-GFP and p25-GFP plasmids were from Addgene. Rab3a 3'-UTR (NM_009001) was amplified with 5' -TTATATAT ACTAGTGCCACTTCCCTTCCCTGCTGCC-3' (Forward-SpeI)and5'-AT ATAATATAAGCTTCAGGGTGCGGAAATTC

ATTAAATTCT-3' (Reverse-HindIII) and cloned in miRNA reporter (Ambion). miRNAs were cloned and expressed by The BLOCK-iT Pol II miRNA and RNAi Expression Vector Kit (Life Technologies).

Cell culture. Neuro-2a (a mouse neuroblastoma cell line), C2C12 (a mouse myogenic cell line), and HEK293 (a human embryonic kidney cell line) were grown in standard medium according to the manufacturer's medium protocol (American Type Culture Collection). Cells were cultured on six-well plates and coexpressed with different plasmids, miRNA expression vector, and miRNA reporter using Lipofectamine 2000 (Life Technologies) for $72 \mathrm{~h}$ and collected for analysis.

Animals and tissue preparation. Three- to 4-month-old WT FVB mice and mSCS mice that express the $\varepsilon$ L269F mutation (Gomez et al., 1997) were used in this study. nNOS KO mice were from The Jackson Laboratory. All drug treatments and surgical procedures followed the animal care and use protocols established by the institutional animal care and use committee. Sciatic nerve axotomy (denervation) was described previously (Zhu et al., 2011). All mice used in this study were age-matched males ( 3 to 4 months of age). Sciatic nerve (SN) used for investigation was dissected from lumbar region to the proximal terminal of the tibialis anterior (TA) muscle. Mouse lumbar region (L1-6) was selected for investigation of Rab3a mRNA and protein expression level in spinal cord (SC). Table 1 shows the details of human SCS and CEAD biopsies used in our investigation. De-identified muscle biopsies were used in accordance with the respective institutional review boards.

Drug administration. 7-Nitroindazole (7-NI; $50 \mathrm{mg} / \mathrm{kg}$ ) was administered intraperitoneally daily for $9 \mathrm{~d}$ (Ikeda et al., 1998). Control mice were treated with DMSO or saline $(0.9 \% \mathrm{w} / \mathrm{v}$; ThermoFisher Scientific).

RNA extraction, cDNA synthesis, and quantitative real-time PCR. RT-PCR and quantitative RT-PCR (qRT-PCR) were performed as described previously (Zhu et al., 2011). To measure miRNA expression, cDNA was synthesized and amplified with the NCode miRNA FirstStrand cDNA Synthesis and qRT-PCR kit (Life Technologies), in which U6 was selected as internal control and 100 ng of miRNA-based cDNA
Table 1. Human SCS and CEAD biopsies used in this study

\begin{tabular}{clll}
\hline Disorder & Mutation & Muscle & Reference $^{a}$ \\
\hline SCS & MutantAChR & & \\
1 & deltaS268F & Anconeus & Gomez et al., 2002 \\
2 & $\alpha$ N217K & Anconeus & Engel et al., 1996 \\
3 & $\beta$ M266M & Anconeus & Gomez et al., 2002 \\
CEAD & Mutant ColQ & & \\
1 & Q211X and C400Y & Anconeus & Denning et al., 2007 \\
2 & C397S and D370N & Anconeus & Denning et al., 2007 \\
3 & Y404D, C397S, and D370N & Anconeus & Denning et al., 2007 \\
4 & 275 insC and Q211X & Intercostal & Shapira et al., 2002 \\
5 & IVS2 + 1G $>$ C/IVS2 + 1G $>C$ & Quadriceps & Mihaylova et al., 2008 \\
\hline
\end{tabular}

${ }^{a}$ Tissue may be from patients not part of these reports, but bearing the indicated mutation.

Table 2. Sequences used for qRT-PCR

\begin{tabular}{|c|c|}
\hline & Sequence $\left(5^{\prime}-3^{\prime}\right)$ \\
\hline \multicolumn{2}{|l|}{ GAPDH } \\
\hline Sense & GAAGGGCTCATGACCACAGT \\
\hline Antisense & GTTCAGCTCTGGGATGACCT \\
\hline \multicolumn{2}{|l|}{ Rab3a } \\
\hline Sense & GAGGAGTCATTTAATGCAGTGCAG \\
\hline Antisense & CAAAGAACTCAAAGCCCAGGTGGT \\
\hline U6 & CTTCGGCAGCACATATACTAAA \\
\hline mmu-miR-1a (MIMAT0000123) & TGGAATGTAAAGAAGTATGTAT \\
\hline mmu-miR-133a (MIMAT0000145) & ITTGGTCCCCTTCAACCAGCTG \\
\hline mmu-miR-206 (MIMAT0000239) & $\overline{\text { TGGAATGTAAGGAAGTGTGTGG }}$ \\
\hline mmu-miR-124 (MIMAT0000134) & TAAGGCACGCGGTGAATGCC \\
\hline mmu-miR-124 ${ }^{\text {mut }}$ & ITTCCGTCGCGGTGAATGCC \\
\hline mmu-miR-142 (MIMAT0000155) & $\overline{\text { TGTAGTGTTTCCTACTTTATGGA }}$ \\
\hline mmu-miR-142 ${ }^{\text {mut }}$ & TACGGAGCCTCCTACAATATGGA \\
\hline mmu-miR-370 (MIMAT0001095) & GCCTGCTGGGGTGGAACCTGGT \\
\hline mmu-miR-486 (MIMAT0003130) & TCCTGTACTGAGCTGCCCCGAG \\
\hline
\end{tabular}

was used for investigation (Peltier and Latham, 2008). ImageJ version 5.3 was used for semiquantitative study of Rab3a expression in SN. Table 2 shows the sequences used for qRT-PCR.

Western blotting. Immunoblotting was done as described previously (Zhu et al., 2011). Protein expression levels were quantified by scan densitometry using ImageJ.

Tissue staining and imaging. Tissue fixation, immunohistochemistry, and confocal fluorescence microscopy on serial TA muscle cryosections were as described previously (Zhu et al., 2011). ImageJ was used to determine the fraction of NMJs labeled with specific antibodies.

Calpain activity assay. The calpain activity detection kit, buffer, and procedures were as described previously (Zhu et al., 2011).

Cdk5 kinase assay. Cdk5 activity assay was as described previously (Smith et al., 2006). Tissue was homogenized with lysis buffer. The supernatants $(500 \mu \mathrm{g})$ were then collected and immunoprecipitated with Cdk5 antibody $(5 \mu \mathrm{g})$. The Cdk5 immunoprecipitates were washed twice with the lysis buffer and twice with a kinase buffer containing the following (in mM): 50 Tris, $\mathrm{pH} 7.5,5 \mathrm{MgCl}_{2}, 1$ EGTA, 1 EDTA, 40 $\beta$-glycerophosphate, $20 \mathrm{p}$-nitrophenylphosphate, 0.1 sodium vanadate, and 1 DTT. Kinase activity was measured in a total volume of $50 \mu \mathrm{l}$ of kinase assay buffer with $0.1 \mathrm{~mm}\left[\gamma_{-}{ }^{32} \mathrm{P}\right] \mathrm{ATP}$ (PerkinElmer) and $10 \mu \mathrm{g}$ of histone $\mathrm{H} 1$ (Calbiochem) at $30^{\circ} \mathrm{C}$ for $60 \mathrm{~min}$. The reaction was stopped by adding SDS sample loading buffer $(4 \times)$. Samples were separated by SDS-PAGE gel (15\%), transferred to nitrocellulose membrane, and autoradiographed to detect phosphorylation of histone $\mathrm{H} 1$. Cdk 5 activity in different tissue samples was normalized via the ratio of phosphorylated histone $\mathrm{H} 1$ to internal Cdk5 expression.

$n N O S$ activity detection via assay and enzyme histochemistry. Cells and muscle tissue were homogenized via lysis buffer supplemented with protease inhibitor and $5 \mu \mathrm{M}$ NG-iminoethyl-L-ornithine. Protein samples $(10 \mu \mathrm{g})$ were analyzed with the Ultrasensitive Colorimetric NOS Assay Kit following the manufacturer's protocol (Oxford Biomedical Research). nNOS activity was detected on muscle slides using the NADPH 

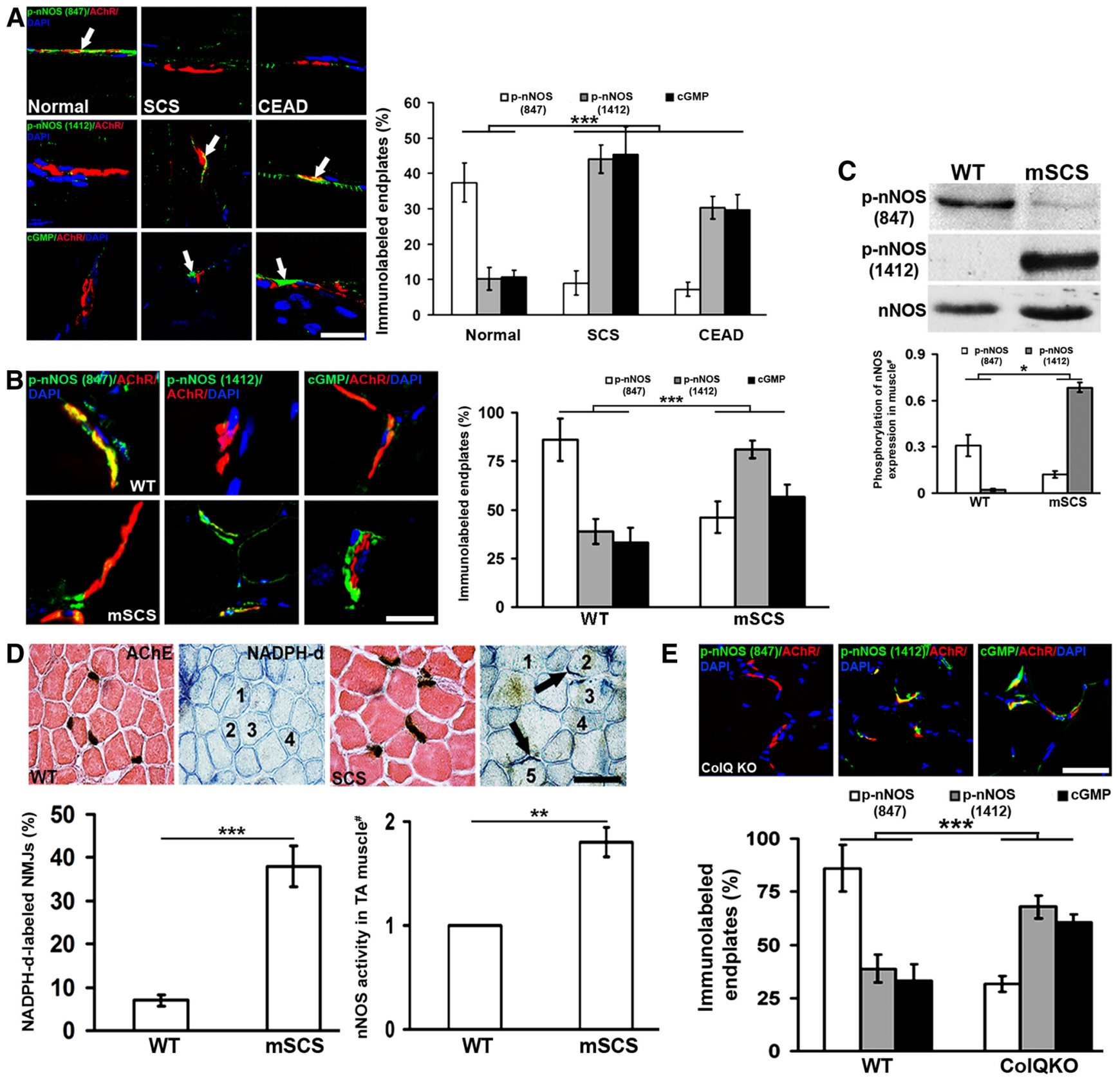

Figure 1. nNOS is abnormally activated at NMJs in SCS and CEAD. A, Left: Immunolabeling using antibodies to nNOS p-S847, nNOS p-S1412, and cGMP in cryosections from muscle biopsies from patients with SCS $(n=3)$ and CEAD $(n=4)$ compared with control muscle $(n=3)$. nNOS p-S847 immunolabeling (green) was strongly colocalized with NMJs (labeled with TxR- $\alpha$ BT, red) in normal human muscle, but to a lesser degree in SCS and CEAD (arrows). nNOS p-S1412 (green) and CGMP (green) immunolabeling were highly colocalized with NMJs in SCS and CEAD muscles, but to a lesser degree in normal human muscle. CGMP immunolabeling was associated with the presynaptic neuron at the NMJ and colocalized with synaptophysin (not shown). Right: Fraction of nNOS p-S847-labeled endplates in normal human muscle was significantly greater than in SCS and CEAD muscle. The fraction of nNOS p-S1412-labeled endplates in SCS and CEAD was significantly greater than in normal human muscle. The fraction of CGMP-labeled endplates was higher in SCS and CEAD than in normal human muscle. Scale bar, $15 \mu \mathrm{m}$. ${ }^{* * *} p<0.001$, Student's $t$ test. B, Left: Cryosections of transgenic mSCS TA muscle immunolabeled using antibodies to nNOS p-S847, nNOS p-S1412, and CGMP. nNOS p-S847 immunolabeling (green) was strongly colocalized with NMJs labeled with TxR- $\alpha$ BT (red) in normal mouse muscle, but to a lesser degree in mSCS (arrows). nNOS p-S1412 (green) and CGMP (green) immunolabeling were highly colocalized with NMJs in mSCS, but to a lesser degree in WT muscle. Right: The fraction of nNOS p-S847-labeled endplates in WT muscle was significantly greater than in mSCS. The fraction of nNOS p-S1412-labeled and cGMP-labeled endplates was significantly greater in mSCS muscle than in WT muscle $(n=5)$. Scale bar, $15 \mu \mathrm{m}$. ${ }^{* *} p<0.001$, Student's t test. C, Immunoblots of nNOS p-S847 and p-S1412 protein in WT and mSCS TA muscle. The expression level of nNOS p-S847 was higher in WT than mSCS TA muscle, whereas the level of nNOS $p$-S1412 expression was higher in mSCS than in WT ( $n=3$ ). * $p<$ 0.05, Mann-Whitney $U$ test. D, Histochemical measurement of nNOS activity using NADPH-d in WT and mSCS cryosections. Serial TA muscle sections were labeled for cholinesterase (dark brown; AChE) to localize endplates and NADPH-D (dark blue) to identify nNOS activity. Top: Numbers on NADPH-D-labeled fibers correspond to the fibers with AChE-labeled fibers in adjacent sections. Bottom left: The fraction of NADPH-D-labeled endplates in mSCS muscle was significantly greater than in WT muscle $(n=5)$. ${ }^{* * *} p<0.001$, Student's $t$ test. Bottom right: $\mathrm{nNOS}$ activity in TA muscle homogenates was twice that of WT muscle, as measured by colorimetric assay $(n=5)$. Scale bar, $90 \mu \mathrm{m} .{ }^{* *} p<0.01$, Mann-Whitney $U$ test. $\boldsymbol{E}$, Top: Immunolabeling using antibodies to nNOS p-S847, nNOS p-S1412, and GMPP in cryosections of ColQ KO muscle. nNOS p-S847 immunolabeling (green) was strongly colocalized with NMJs (red) in normal mouse muscle, but to a lesser degree in ColQ KO (arrows). nNOS p-S1412 (green) and cGMP (green) immunolabeling were highly colocalized with NMJs in ColQ K0, but to a lesser degree in WT. Bottom: The fraction of nNOS p-S847-labeled endplates in WT muscle was significantly greater than in ColQ K0. The fraction of nNOS p-S1412-labeled and cGMP-labeled endplates was significantly greater in ColQ KO muscle than in WT muscle $(n=3)$. Scale bar, $50 \mu \mathrm{m}$. ${ }^{* * *} p<0.001$, Student's $t$ test. 
B
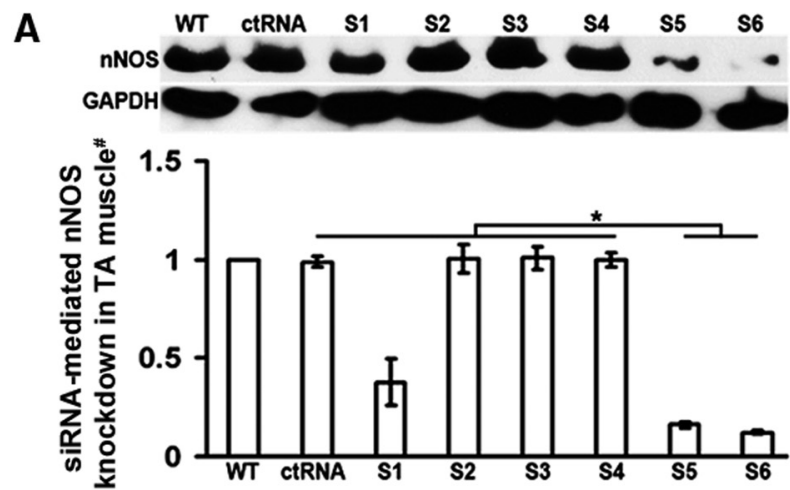

mscs
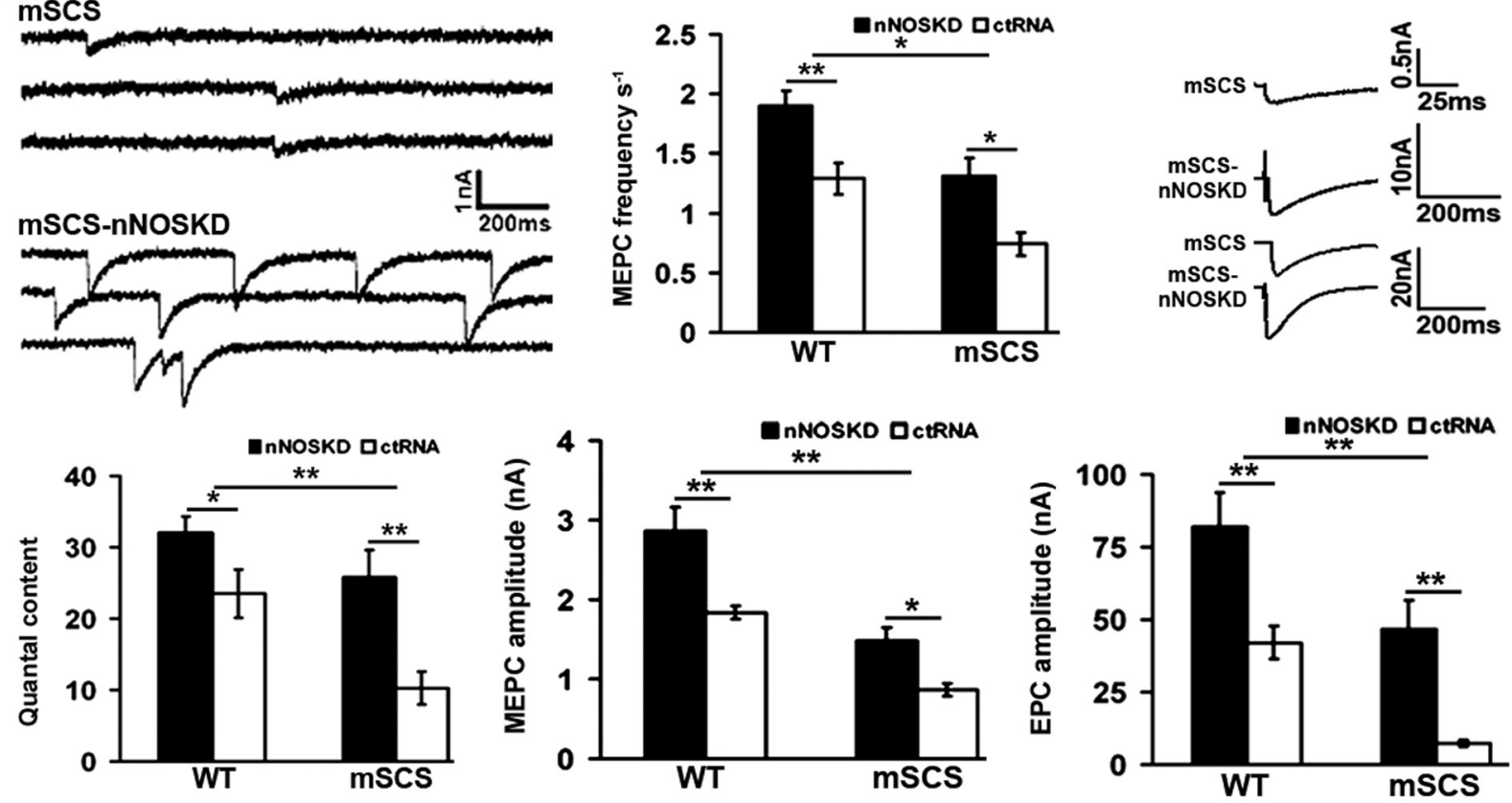

C
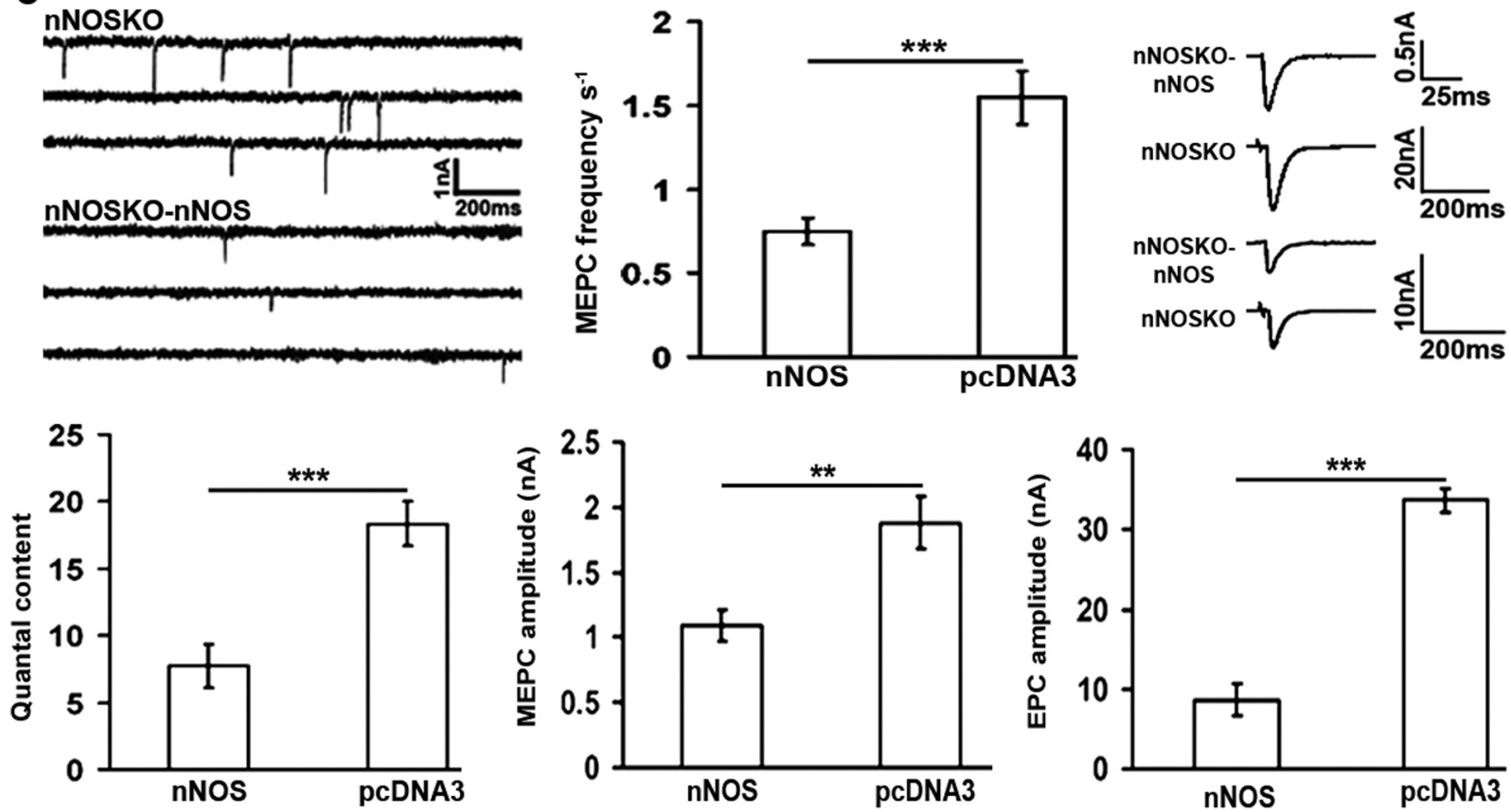

Figure 2. nNOS activity negatively regulates neuromuscular transmission in normal and mSCS muscles. A, nNOS silencing in WT TA muscle in vivo. Comparison of nNOS protein levels by immunoblot after electroporation of WT TA muscle with six nNOS-specific siRNA sequences (S1-S6) and scrambled RNA as ctRNA. Nine days after electroporation, nNOS protein levels were significantly decreased by sequences $\mathrm{S5}$ and $\mathrm{S6}$. " Normalized to untreated WT $(n=3) .{ }^{*} p<0.05$, Mann-Whitney $U$ test. $\boldsymbol{B}$, nNOS silencing increases synaptic strength (Figure legend continues.) 
diaphorase (NADPH-d) reaction as described previously (Grozdanovic et al., 1995). Endplates were labeled using acetyl cholinesterase reaction as described previously (Koelle and Friedenwald, 1949).

miRNA report assay. Rab3a 3'-UTR was cloned in the pMIR-REPORT system (Ambion) and coexpressed with the miRNA vector system (Life Technologies) in HEK 293 cells in which luciferase activity was used to exhibit miRNA effects on a target gene. $\beta$-galactosidase activity was used to normalize the miRNA effect. Luciferase and $\beta$-galactosidase assay kits (Promega) were used for activity detection.

Intramuscular electroporation-mediated gene delivery and knock-down. Electrically mediated gene delivery and siRNA knock-down (KD) in mouse TA muscle were performed as described previously (Zhu et al., 2011).

In vitro electrophysiology. Voltage-clamp analysis of sciatic-tibialis nerve-muscle preparations was performed as described previously (Zhu et al., 2011).

Quantitative studies in tissue sections. Quantification of endplate labeling was performed as described previously (Zhu et al., 2011).

Bioinformatics. miRNA sequences and target gene prediction was conducted using miRNA-focused engine servers (www.mirbase.org and www.targetscan.org). Gene-specific RNAi design was done with siRNA Target Finder (Ambion).

Statistical analysis. Data are expressed as mean \pm SD. Statistical analyses were performed by Student's $t$ test, two-way ANOVA, and the nonparametric Mann-Whitney $U$ test.

\section{Results \\ nNOS is abnormally activated at the NMJ in congenital myasthenic syndromes}

Reduced presynaptic function in the "postsynaptic" congenital myasthenic syndromes such as SCS and CEAD suggests the presence of a retrograde signaling pathway (Engel et al., 1977; Engel et al., 1982; Gomez et al., 1997). The nNOS-NO pathway has been linked to retrograde synaptic signaling in a wide range of species and synapses (Aonuma et al., 2000; Etherington and Everett, 2004; Graves et al., 2004). nNOS activity is modulated by direct $\mathrm{Ca}^{2+}$-calmodulin binding, as well as by the relative extent of phosphorylation at serine residues 847 (inhibition; p-S847) and 1412 (activation; p-S1412) (Hayashi et al., 1999; Rameau et al., 2007). To determine whether the nNOS pathway is activated in SCS and CEAD, we first used antisera specific for p-S847 and

$\leftarrow$

(Figure legend continued.) in SCS and WT mouse NMJ. Representative traces of spontaneous synaptic activity measured as MEPCs (voltage clamped at $-60 \mathrm{mV}$ ) from excised, intact TA muscle-nerve preparations $9 \mathrm{~d}$ after electroporation of siRNA. Raw data show spontaneous MEPCs recorded in $\mathrm{mSCS}$ muscle treated with ctRNA (upper) or nNOS siRNA sequence $S 5$ and $\mathrm{S6}$. nNOS silencing produced an increase in spontaneous synaptic activity. Graphs: $\mathrm{nNOS}$ silencing in TA muscle caused a $>40 \%$ increase in MEPC frequency $\left(n=18,{ }^{*} p<0.05\right)$ in mSCS TA and a $>30 \%$ increase in WT TA $\left(n=18,{ }^{* *} p<0.01\right)$. nNOS silencing in TA caused a $150 \%$ increase in QC $\left(n=13,{ }^{* *} p<0.01\right)$ in mSCS TA and a $25 \%$ increase in WT TA $\left(n=9,{ }^{*} p<0.05\right)$. nNOS silencing in TA caused a 40\% increase in MEPC amplitude in $\mathrm{mSCS} \mathrm{TA}(1.48 \pm 0.17 \mathrm{nA}, n=18$, vs $0.87 \pm 0.08 \mathrm{nA}$, respectively, $\left.n=10,{ }^{*} p<0.05\right)$ and a $>35 \%$ increase in WT TA ( $2.86 \pm$ $0.3 \mathrm{nA}, n=10$, vs $1.84 \pm 0.08 \mathrm{nA}$, respectively, $n=7$, ** $p<0.01)$. EPC amplitudes were increased $>2$-fold in mSCS TA muscle ( $16.71 \pm 10.07 \mathrm{nA}, n=14$, vs $7.29 \pm 1.13 \mathrm{nA}, n=7$, respectively, $\left.{ }^{* *} p<0.01\right)$ and nearly 2 -fold in WT TA $(82.08 \pm 11.74 \mathrm{nA}, n=9$, vs $42.09 \pm$ $5.79 \mathrm{nA}, n=7$, respectively, $\left.{ }^{* *} p<0.01\right)$ by nNOS KD. Traces: Average MEPCs and EPCs recorded from excised muscle. C, Expression of nNOS in TA muscle of nNOS KO mice reduced synaptic strength in NMJ. Voltage-clamp study of excised, intact TA muscle-nerve preparations $5 \mathrm{~d}$ after plasmid electroporation. Recordings of MEPCs taken from TA muscle of nNOS KO mice treated with empty vector (top) or nNOS expression plasmid (bottom). Graphs: nNOS expression in TA muscle of nNOS mice reduced MEPC frequency and QC by $>2$-fold $\left(n=8,{ }^{* * *} p<0.001\right)$ compared with the effect of empty vector $(n=7)$. nNOS expression in TA muscle of nNOS mice reduced MEPC amplitude $>40 \%\left(n=8,{ }^{* * *} p<0.001\right)$ and EPC amplitude $>70 \%(n=7$ control; $n=8$, nNOS plasmid, ${ }^{* * *} p<0.001$ ). Traces: Average MEPCs (spontaneous) and evoked EPCs (evoked release) indicates an increase in MEPC and EPC amplitude after nNOS expression in contralateral TA muscle.
p-S1412 nNOS epitopes in immunofluorescence colocalization studies with the NMJ using fresh-frozen muscle sections from diagnostic muscle biopsies from patients with SCS $(n=3)$ or CEAD $(n=4)$ (Fig. $1 A$, left). The genotypes of the patients are shown in Table 1. Compared with normal human muscle $(n=3)$, both SCS and CEAD have significantly higher proportions of NMJs labeled with p-S1412 antibody (44\% and 30\% vs $10 \%$, respectively, $p<0.001$ ) and significantly lower proportions labeled for p-S847 antibody ( $9 \%$ and $7 \%$ vs $37 \%$, respectively, $p<$ 0.001 ) (Fig. $1 A$, right). NO is a highly unstable molecular species that cannot be readily measured in tissue sections (Archer, 1993). However, because one key effect of NO is to activate soluble guanylyl cyclase, which generates cGMP, we used antibody specific for cGMP to localize this molecule in serial sections of these muscle biopsies. We found significantly higher numbers of NMJs labeled for CGMP in SCS and CEAD muscle (45\% and $30 \%$ vs $10 \%$, respectively, $p<0.001$; Fig. $1 A$ ). cGMP immunolabeling was colocalized with immunolabeling for the nerve terminal antibody, synaptophysin (data not shown), suggesting that increased postsynaptic nNOS activity in SCS increases nerve terminal cGMP.

We tested for similar changes using a well characterized transgenic mouse model for SCS expressing the $\varepsilon \mathrm{L} 269 \mathrm{~F}$ mutation (Gomez et al., 1997; Groshong et al., 2007; Zhu et al., 2011) Figure $1 B$ shows that in WT TA, muscle only $\sim 33 \%$ of NMJs show p-S1412 immunoreactivity, whereas $86 \%$ label for the p-S847 antibody. mSCS NMJs, however, show the reverse pattern, with $\sim 81 \%$ showing p-S1412 immunoreactivity and $46 \%$ labeling for the $\mathrm{p}$-S847 antibody $(p<0.001)$. Similarly, only $\sim 33 \%$ of NMJs label for cGMP, whereas in SCS mice, $56 \%$ of NMJs contain detectable cGMP immunoreactivity $(p<0.001)$, which colocalized with synaptophysin (data not shown). We found similar changes in the relative proportions of the phosphorylated forms of nNOS in immunoblot studies (Fig. 1C). p-S847 was readily detectable in WT muscle homogenates, but only faintly present in mSCS muscle, whereas p-S1412 was absent in WT muscle and present at high levels in SCS muscle. The relative levels of nNOS protein in muscle were not different between the mouse groups. Increased amounts of activated forms of nNOS should correspond to changes in nNOS activity. We used nitro blue tetrazolium to histochemically detect nNOS activity in muscle sections (Grozdanovic et al., 1995) and colocalized to NMJs in serial sections using a cholinesterase histochemical stain (Fig. $1 D$, top). In WT muscle, only $\sim 6 \%$ of NMJs were labeled for activated nNOS, whereas in mSCS muscle, $\sim 39 \%$ had histochemically detectable nNOS activity (Fig. $1 D$, bottom left). These measurements were also consistent with colorimetric assay of nNOS activity in muscle homogenates, which showed that nNOS activity in mSCS muscle was approximately twice that of WT muscle (Fig. 1D, bottom right). These findings correlate well with the more sensitive immunolabeling for nNOS phospho-epitopes and show that in mSCS muscle, nNOS activity is increased at the NMJ (Fig. 1B).

Finally, we studied the pattern of nNOS activity in muscle sections from a mouse model of CEAD generated by targeted disruption of the gene encoding ColQ. In homozygous ColQ ${ }^{-1-}$ (ColQ KO) TA muscle sections, only 35\% of NMJs labeled for the p-S847 antibody compared with $83 \%$ of WT mice, whereas $70 \%$ of ColQ KO NMJs labeled with the p-S1412 antibody and 60\% of NMJs labeled with the cGMP antibody compared with $33 \%$ of WT NMJs (Fig. 1E). These findings demonstrate that the NOnNOS signaling pathway is abnormally activated at the NMJ, 

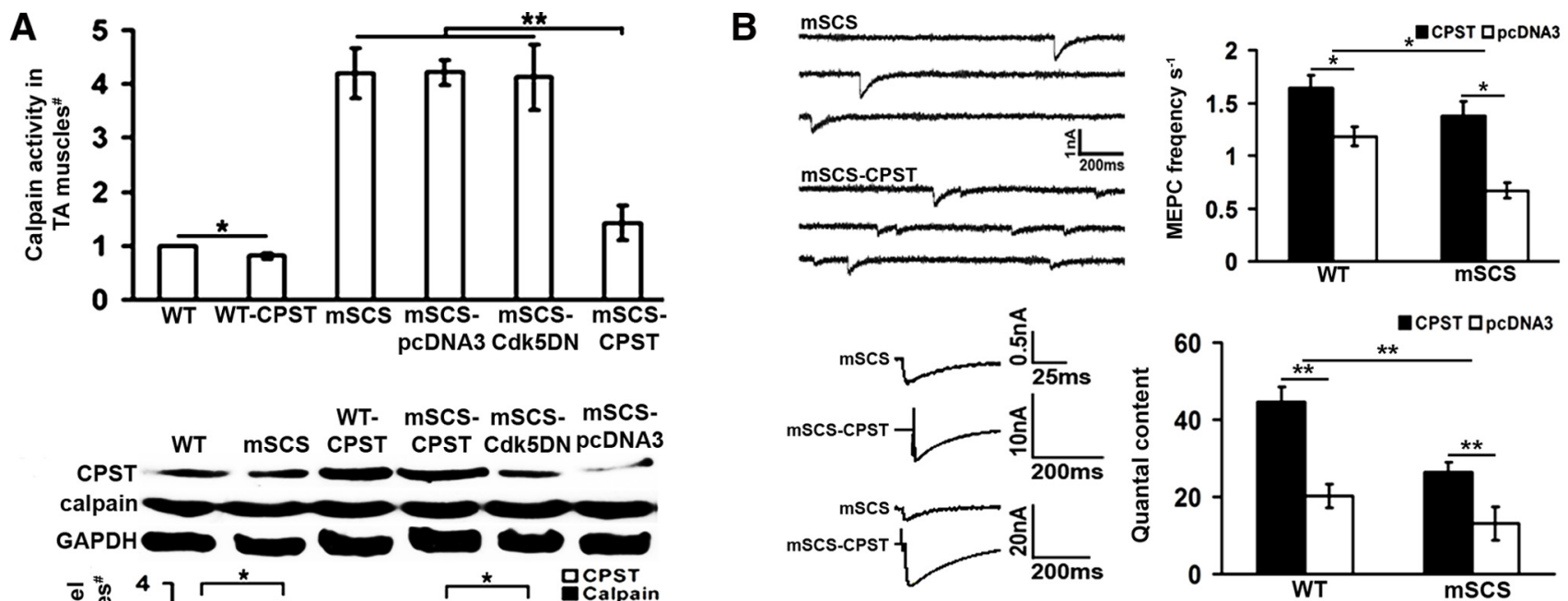

WT- mSCS- mSCS- mSCSWT mSCS CPST CPST Cdk5DN PCDNA3
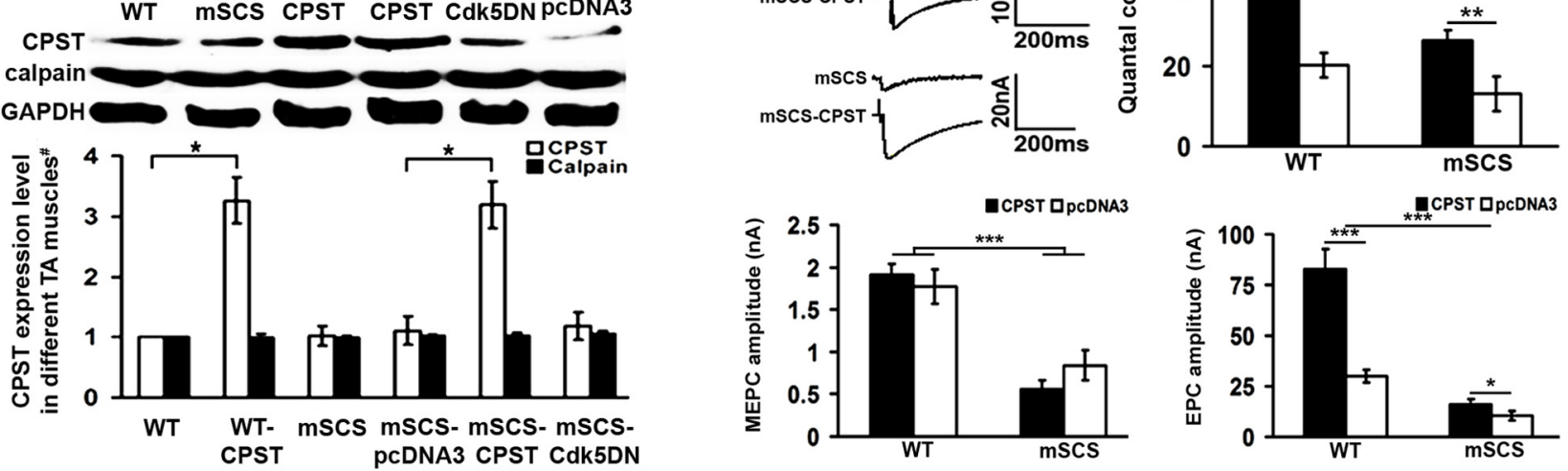

C

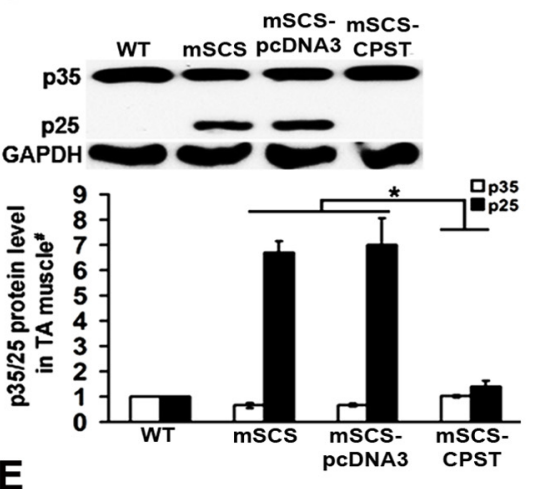

D
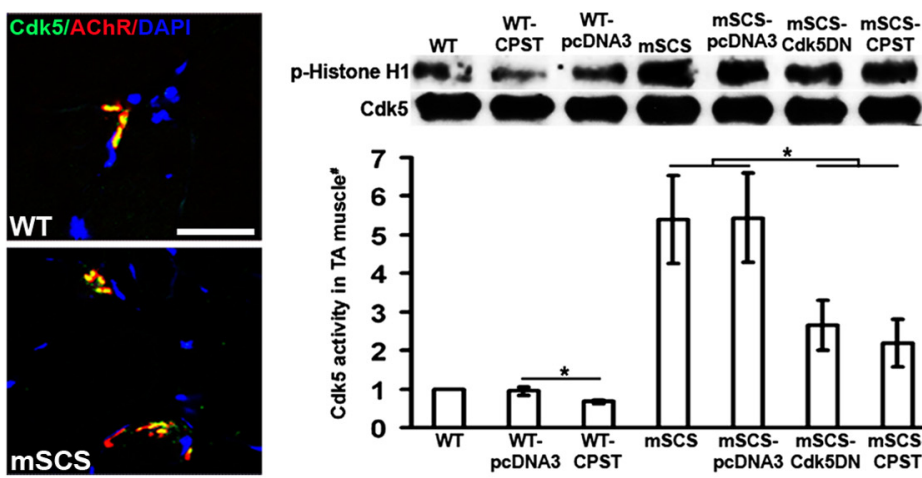

mscs
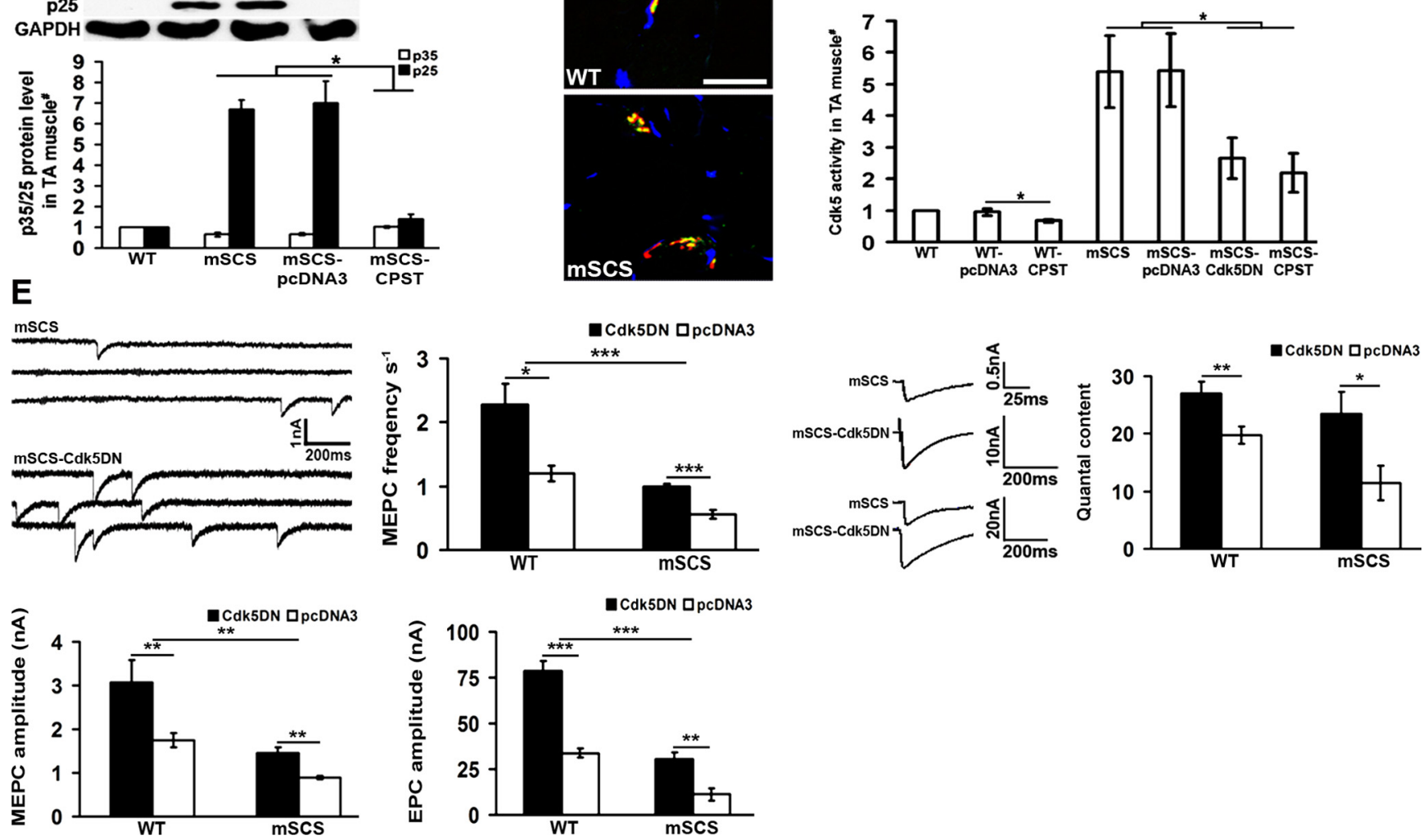

Figure 3. Calpain and Cdk5 activities negatively regulate neuromuscular transmission in normal and mSCS muscles. $A$, Top: Calpain levels measured in TA muscle homogenates of WT mice, mSCS mice, and mice treated with by electroporation of plasmid expressing (PST, the dominant-negative form of Cdk5 (Cdk5DN), or empty vector (pcDNA3) $5 \mathrm{~d}$ previously. Calpain activity in mSCS muscle are $4 \times$ those of WT. CPST decreased calpain activity in mSCS muscle, but neither Cdk5DN nor pcDNA3 had any effect. ${ }^{*}$ Normalized to WT calpain activity $(n=5) .{ }^{* *} p<0.01$, Mann-Whitney $U$ test. Bottom: Immunoblots of CPST and calpain expression in WT and mSCS TA muscle homogenates. CPST was markedly increased in CPST-treated WT and mSCS TA muscle $5 \mathrm{~d}$ after electroporation of CPST. Treatment of WT and mSCS TA muscles with CPST and Cdk5DN had no effects on calpain expression $(n=3) .{ }^{*} p<0.05$, Mann-Whitney $U$ test. $B$, Voltage-clamp study of excised, intact TA muscle-nerve preparations $5 \mathrm{~d}$ after electroporation of CPST expression vector. Representative traces spontaneous synaptic activity (MEPCs) recorded from TA muscle (Figure legend continues.) 
leading to an increase in presynaptic cGMP in clinical and experimental conditions associated with cholinergic overactivity.

\section{nNOS activity negatively regulates neurotransmitter release in normal and mSCS NMJ}

To test for a direct correlation between the changes in nNOS activity and quantal release in $\mathrm{mSCS}$ and WT muscle, we used voltage-clamp analysis of spontaneous and evoked synaptic activity in the NMJ to study mice deficient in nNOS by siRNAmediated nNOS gene silencing. Figure $2 A$ shows the KD effect on nNOS expression in TA muscle $9 \mathrm{~d}$ after electroporation with 6 nNOS-specific siRNA sequences, as we described previously for silencing type 1 IP3 receptor (Zhu et al., 2011). Segments S5 and S6 led to $90 \%$ reduction at nNOS protein levels compared with little or no effect of control (scrambled) RNA (ctRNA) or other nNOS siRNAs. Nine days after electroporating segments S5 and S6, combined siRNA-mediated nNOS silencing in mSCS muscle led to a significant increase in miniature endplate current (MEPC) frequency $\left(1.31 \pm 0.15 \mathrm{~s}^{-1}\right.$ vs $0.74 \pm 0.10 \mathrm{~s}^{-1}$, respectively, $n=18, p<0.05)$ and quantal content (QC) $(25.83 \pm 3.74$ vs $10.28 \pm 2.31$, respectively, $n=13, p<0.01$ ) to normal levels compared with the effect of ctRNA. This suggests that the changes seen in nNOS activation markers in mouse and human SCS and

$\leftarrow$

(Figure legend continued.) of mSCS mice treated with empty vector (top) or CPST expression plasmid (bottom). Graphs: CPST expression in TA muscle of mSCS mice increased MEPC frequency $(n=27)$ and QC $(n=13)$ by more than 2 -fold $\left({ }^{* * *} p<0.001\right)$ compared with the effect of empty vector $(n=12)$. CPST expression in TA muscle of WT mice increased MEPC frequency by $28 \%\left(n=27,{ }^{*} p<0.05\right)$ and QC by more than 2 -fold $\left(n=13,{ }^{*} p<0.01\right)$ compared with the effect of empty vector ( $n=16, \mathrm{MEPC}$ frequency; $n=10,0 \mathrm{Q}$ ). CPST expression in TA muscle of mSCS mice reduced MEPC amplitude by $33 \%\left(n=17,{ }^{* * *} p<0.001\right)$ compared with control plasmid $(n=23)$. CPST expression in WT TA muscle had no significant effect on MEPC amplitude. CPST expression in TA muscle of mSCS mice increased EPC amplitude by $>2$ fold ( $n=13$, $\left.{ }^{*} p<0.05\right)$ compared with control plasmid $(n=12)$. CPST expression in TA muscle of WT mice increased EPC amplitude by $>2$-fold $\left(n=13,{ }^{* *} p<0.001\right)$ compared with control plasmid $(n=10)$. Traces: Illustration of average MEPCs (spontaneous) and EPCs (evoked release) indicates an increase in MEPC and EPC amplitude after CPST expression in the contralateral side of the TA muscle. C, Immunoblots (top) and quantitation (bottom) of 335 and 25 protein levels in WT and mSCS TA muscle homogenates from untreated mice or mice treated $5 \mathrm{~d}$ previously with CPST or control plasmid. The 225 polypeptide is present in $\mathrm{mSCS}$ and in mSCS treated in control plasmid, but not seen in WT muscle. The p25 polypeptide is not present in mSCS treated with CPST. "Normalized to WT levels $(n=3)$. ${ }^{*} p<0.05$, Mann-Whitney U test. D, Left: Cryosections of WT or mSCS TA muscle immunolabeled with antibody to Cdk5 (green) show that Cdk5 colocalized with NMJ labeled with TxR- $\alpha$ BT (red) in both mouse types $(n=5)$ ). Scale bar, 25 $\mu \mathrm{m}$. Right: (dk5 activity in TA muscle homogenates estimated as the phosphorylating activity for the substrate histone $\mathrm{H} 1$ was significantly elevated in $\mathrm{mSCS}$ and $\mathrm{mSCS}$ mice treated with pcDNA3, but significantly reduced in mSCS TA muscle treated with CPST or Cdk5DN plasmids $5 \mathrm{~d}$ previously. "Normalized to untreated WT $(n=3) .{ }^{*} p<0.05$, Mann-Whitney $U$ test. $\boldsymbol{E}$, Voltage-clamp study of excised, intact TA muscle-nerve preparations $5 \mathrm{~d}$ after electroporation of Cdk5DN expression vector. Recordings of MEPCs were taken from TA muscle voltage-clamped at $-60 \mathrm{mV}$. Raw data show spontaneous MEPCs recorded in TA muscle of mSCS mice treated with empty vector (top) or Cdk5DN expression plasmid (bottom). Graphs: Cdk5DN expression in TA muscle of $\mathrm{mSCS}$ mice increased MEPC frequency $\left(n=8,{ }^{* * *} p<0.001\right)$ by nearly 2-fold and $Q C\left(n=10,{ }^{*} p<0.05\right)$ by more than 2 -fold $\left({ }^{* * *} p<0.001\right)$ compared with effect of empty vector $(n=8)$. Cdk5DN expression in TA muscle of WT mice increased MEPC frequency by almost 2-fold $\left(n=10,{ }^{*} p<0.05\right)$ and QC by $36 \%\left(n=8,{ }^{* *} p<0.01\right)$ compared with the effect of empty vector ( $n=8, \mathrm{MEPC}$ frequency; $n=6,0 \mathrm{C}$ ). Cdk5DN expression in TA muscle of mSCS mice increased MEPC amplitude by $>60 \%\left(n=10,{ }^{* *} p<0.01\right)$ compared with control plasmid $(n=8)$. Cdk5DN expression in WT TA muscle increased MEPC amplitude by $75 \%$ ( $n=$ $\left.7,{ }^{* *} p<0.01\right)$ compared with control plasmid $(n=6)$. Cdk5 expression in TA muscle of mSCS mice increased EPC amplitude by $>2$ fold $\left(n=8,{ }^{* * *} p<0.001\right)$ compared with control plasmid $(n=8)$. Cdk5 expression in TA muscle of WT mice increased EPC amplitude by more than 2-fold $\left(n=8,{ }^{* *} p<0.01\right)$ compared with control plasmid $(n=6)$. Traces: Illustration of average MEPCs (spontaneous) and EPCs (evoked release) indicates an increase in MEPC and EPC amplitude after CDK5 expression in the contralateral side of TA-muscle.
CEAD muscle may contribute to the impairment of neuromuscular transmission. We next investigated whether modulation of nNOS activity plays a similar role in normal neuromuscular transmission (Fig. 2B). siRNA silencing of nNOS in WT mouse muscle also led to an increase in MEPC frequency $(1.90 \pm 0.13$ $\mathrm{s}^{-1}$ vs $1.29 \pm 0.13 \mathrm{~s}^{-1}$, respectively, $\left.n=18, p<0.01\right)$ and QC (32.04 \pm 2.23 vs $23.53 \pm 3.35$, respectively, $n=9, p<0.05$ ) compared with ctRNA. Therefore, skeletal muscle nNOS activity negatively regulated presynaptic strength. MEPC amplitude, a measure of postsynaptic strength, was also significantly increased in both mSCS and WT muscle after nNOS silencing by $70 \%$ and $55 \%$, respectively, most likely due to an additional effect on $\mathrm{AChR}$ expression. This is consistent with the finding that nNOS silencing in muscle also led to an increased expression of AChR subunit mRNAs (data not shown). The resultant amplitudes of EPCs were significantly increased by approximately 2 -fold in both $\mathrm{mSCS}$ and WT mice after nNOS KD.

Long-term genetic ablation of nNOS in KO mice may lead to other compensatory changes. Therefore, to test for changes attributable to nNOS alone in mice with targeted disruption of the nNOS gene (nNOS KO), we performed voltage-clamp analysis of TA muscle of nNOS KO mice after electroporating TA muscles with either nNOS expression plasmid or control plasmid $5 \mathrm{~d}$ previously (Fig. 2C). TA muscle of nNOS KO mice treated with control plasmid had a normal to increased MEPC frequency and QC compared with WT mice. However, expression of nNOS in the contralateral nNOS KO TA muscle led to a significant reduction in MEPC frequency $\left(0.75 \pm 0.08 \mathrm{~s}^{-1}\right.$ vs $1.55 \pm 0.16 \mathrm{~s}^{-1}$, respectively, $n=8, p<0.001)$ and QC $(7.74 \pm 1.65, n=8$, vs $18.35 \pm 1.68$, respectively, $n=7, p<0.001)$ compared with control plasmid (Fig. 2C). These results demonstrate that in both normal and diseased muscle, nNOS activity negatively regulates quantal activity of neuromuscular transmission, presumably by production of the messenger, NO. Consistent with the nNOSsilencing results, after electroporation of nNOS plasmid to restore nNOS expression in nNOS KO mice, MEPC amplitude was decreased in TA muscle compared with the side treated with control plasmid ( $1.09 \pm 0.12 \mathrm{nA}$ vs $1.88 \pm 0.2 \mathrm{nA}$, respectively, $n=8, p<0.01$ ), suggesting a postsynaptic effect of $\mathrm{NO}$ as well. In agreement with this finding, AChR subunit mRNA levels were increased in nNOS KO mice relative to WT mice and there was a trend for a decrease after transient expression of nNOS plasmid (data not shown). Not surprisingly, the combined effect of restoring $\mathrm{nNOS}$ expression in nNOS KO TA muscle on neuromuscular transmission was a significant decrease in EPC amplitude (7.74 \pm $1.65 \mathrm{nA}, n=8$, vs $33.66 \pm 1.46$, respectively, $n=7, p<0.001$ ) due to the decrease in QC and MEPC amplitude. These findings suggest that inhibition of the nNOS pathway in muscle may be an appropriate therapeutic target to increase synaptic strength in some neuromuscular disorders.

\section{Calpain modulates quantal release through a Cdk5 pathway in normal and mSCS muscles}

To explore the mechanism of nNOS activation in SCS and CEAD, we investigated the role of the $\mathrm{Ca}^{2+}$-dependent protease calpain, which is highly activated in skeletal muscle in conditions of cholinergic excess (Groshong et al., 2007; Zhu et al., 2011). Transgenic expression of human CPST in skeletal muscle corrects impaired neuromuscular transmission in mSCS and significantly increases quantal release in WT mice, presumably through a retrograde effect on presynaptic nerve function, in a pattern similar to the effect of nNOS modulation (Groshong et al., 2007). Cdk5 is believed to negatively regulate presynaptic transmitter release in 

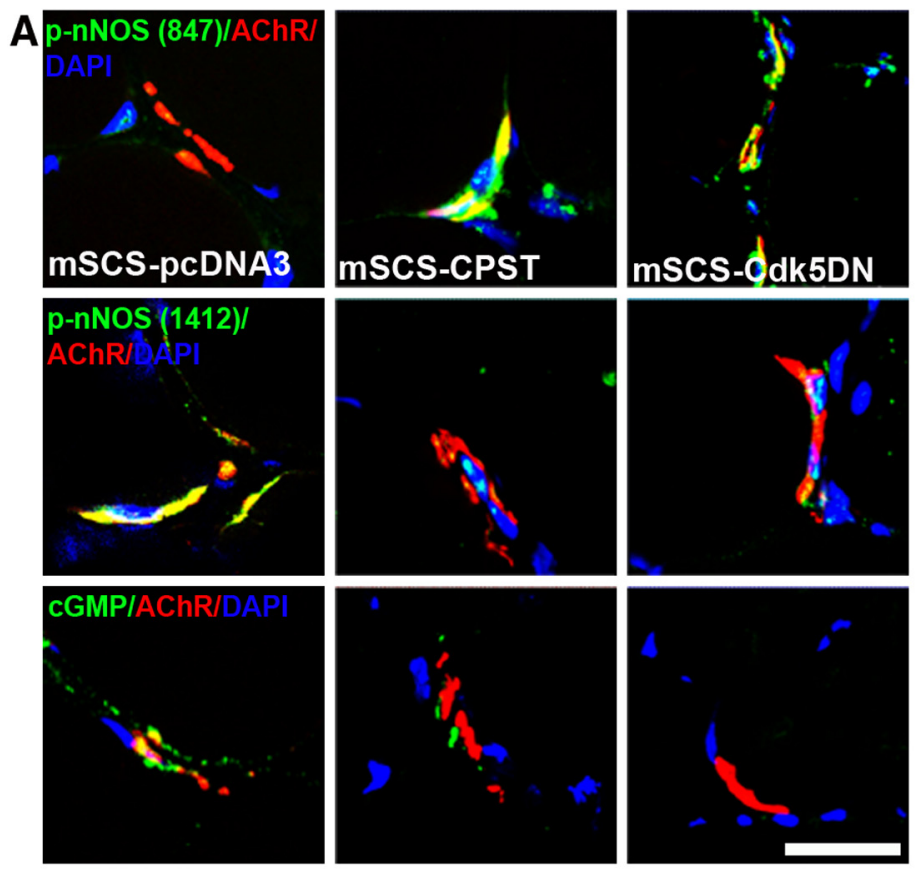

B
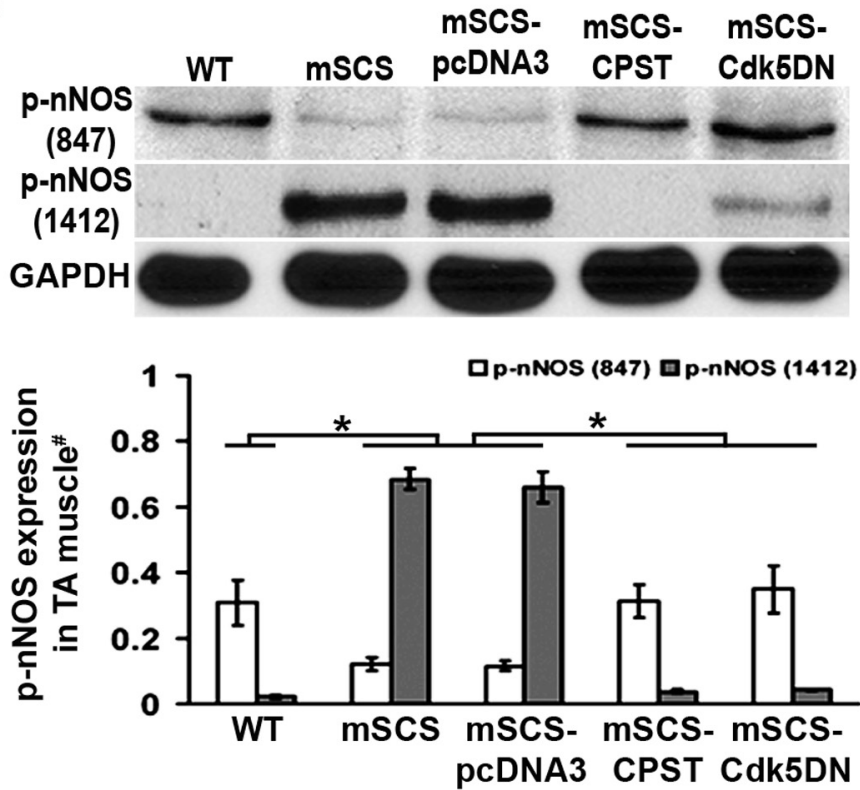

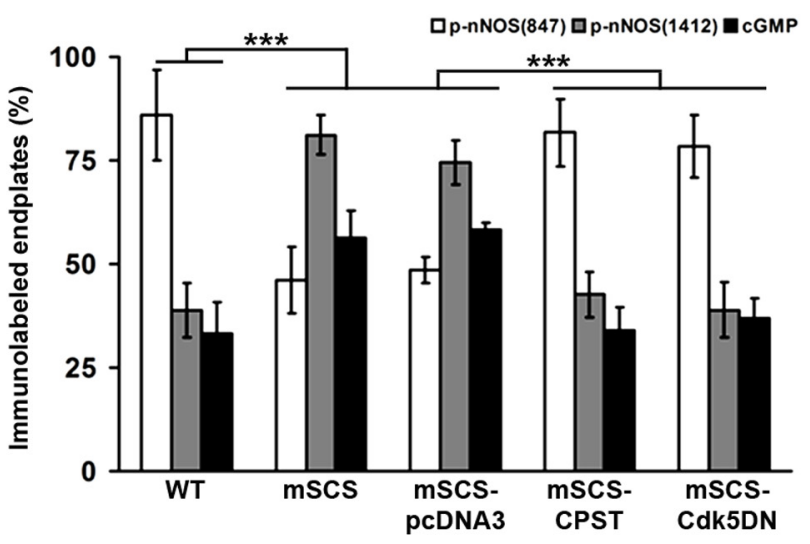

C
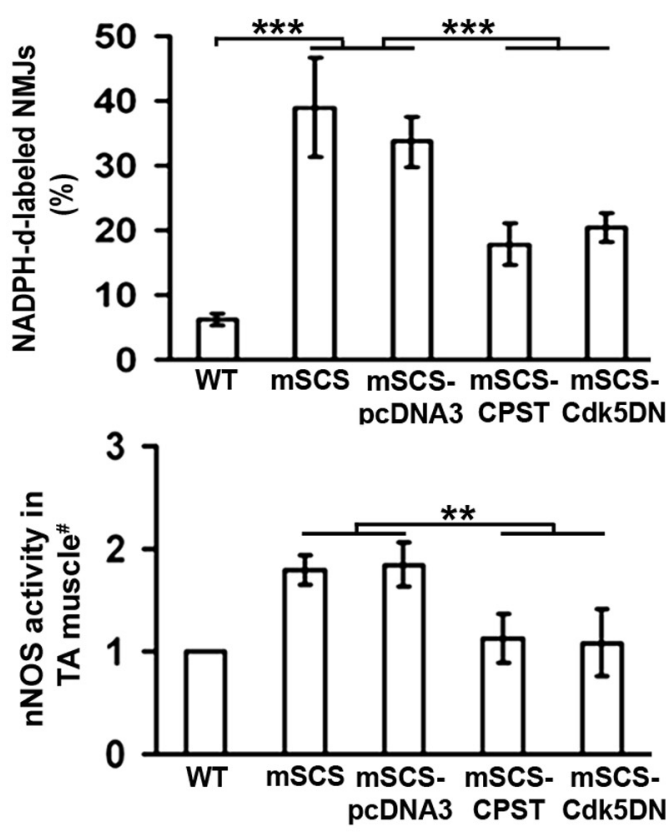

Figure 4. Calpain and Cdk5 increase nNOS activity in mSCS muscle. A, Left: Cryosections of mSCS TA muscle immunolabeled (green) with antibodies to nNOS p-S847, nNOS p-S1412, and CGMP, colocalized with NMJs labeled with TxR- $\alpha$ BT (red) after electroporation with CPST or CDK5DN expression vectors 5 d previously. nNOS p-S847 immunolabeling (green) strongly colocalized with NMJs (red) in mSCS muscle electroporated with CPST or Cdk5DN compared with NMJs in mSCS treated with pcDNA3. nNOS p-S1412 (green) and cGMP (green) immunolabeling was strongly colocalized with NMJs in mSCS plasmid control compared with mSCS treated with CPST or Cdk5DN. Right: Fraction of nN0S p-S847-labeled endplates in mSCS muscle pretreated with CPST or Cdk5DN was significantly greater than in untreated mSCS or control-treated mSCS. The fraction of nNOS p-S1412-labeled and CGMP-labeled endplates was significantly greater in untreated mSCS muscle and control-treated mSCS muscle than in WT and mSCS muscle with CPST or Cdk5DN treatment $(n=5)$. Scale bar, $15 \mu \mathrm{m}$. ${ }^{* * *} p<0.001$, Student's $t$ test. $B$, Immunoblots (top) of p-S847 and p-S1412 phospho-epitopes on nNOS in WT, mSCS, and treated mSCS TA muscles. The expression level (bottom) of nNOS p-S847 was significantly higher in mSCS treated with CPST or Cdk5DN than in untreated mSCS TA muscle, whereas the level of nNOS p-S1412 expression was higher in untreated mSCS than in mSCS with treated with CPST or Cdk5DN $(n=3) .{ }^{*} p<0.05$, Mann-Whitney $U$ test. C, Top: Histochemical measurement of nNOS activity at NMJs in cryosections using NADPH-d in WT, mSCS, and mSCS treated with CPST or Cdk5DN. NMJs were localized using cholinesterase in adjacent slides, as in Figure 1D. The fraction of NADPH-D-labeled endplates in mSCS muscle was significantly greater than in mSCS muscle treated with CPST or Cdk5DN $(n=5)$. ${ }^{* * *} p<0.001$, Student's $s$ test. Bottom: nNOS activity in TA muscle homogenates was significantly higher in untreated mSCS mice and significantly reduced in mSCS muscle electroporated with CPST or Cdk5DN plasmid ( $n=5$ ). ${ }^{* *} p<0.01$, Mann-Whitney U test.

the NMJ (Fu et al., 2005) and calpain is known to modulate Cdk5 activity by cleavage of the Cdk 5 coactivator p 35 to its constitutively active form, p25 (Lee et al., 2000; Smith et al., 2006). We investigated whether acute inhibition of skeletal muscle calpain by electroporation of CPST expression plasmid into TA muscle affected presynaptic motor nerve function and whether this effect was correlated with changes in Cdk5 activity. As shown previously (Zhu et al., 2011), calpain activity is elevated in mSCS muscle (Fig. 3A, top). Five days after electroporation of CPST, CPST protein levels were significantly greater than in control muscle 

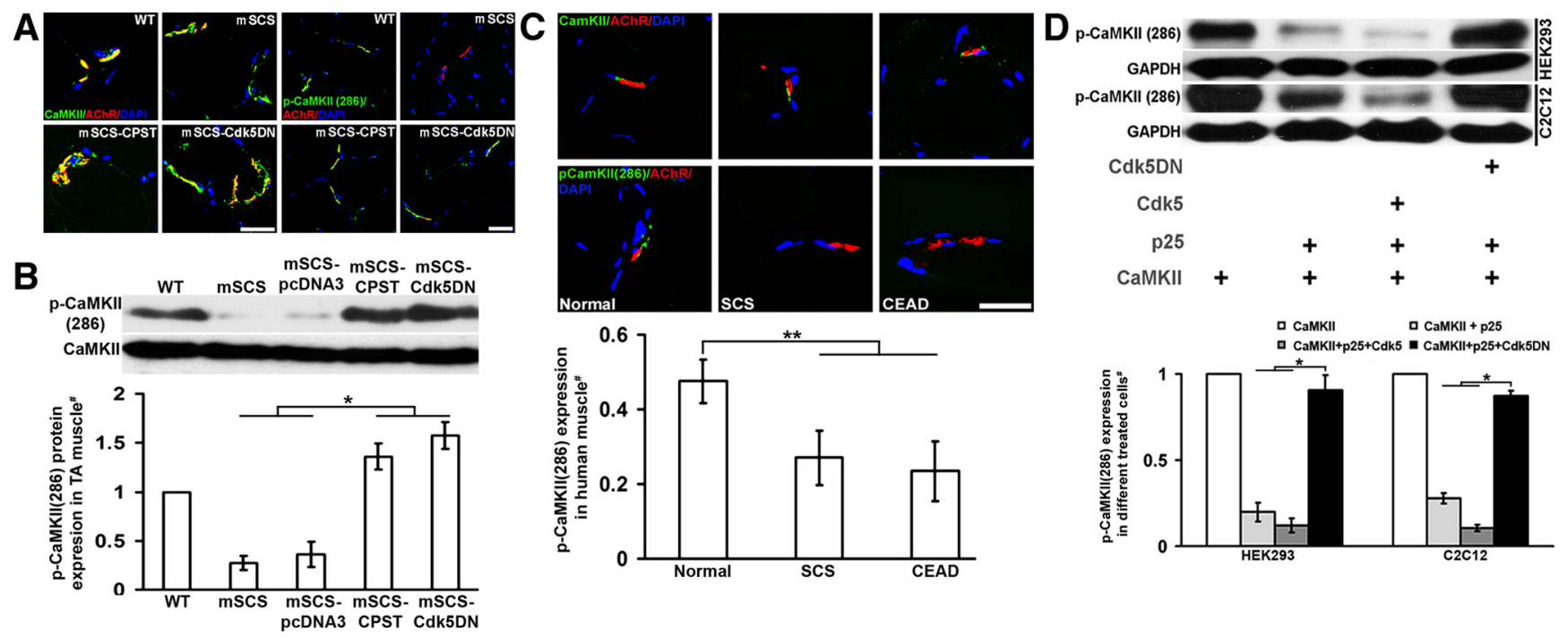

Figure 5. Calpain and Cdk5 act through CaMKII to modulate nNOS in neuromuscular disorders. $A$, Left: Cryosections of mouse TA muscle immunostained (green) for CaMKII protein colocalized with NMJs TxR- $\alpha$ BT (red) in WT, mSCS, and treated mSCS mice. CaMKII colocalized with NMJs in all muscle sections $(n=9)$ ). Scale bar, $15 \mu \mathrm{m}$. Right: Cryosections of mouse muscle immunostained for CaMKII p-T286 phospho-epitope showing that CaMKII p-T286 colocalized with NMJs in WT, but was markedly reduced in mSCS. Treatment of TA muscle with CPST or Cdk5DN plasmid restored CaMKII p-T286 immunostaining $(n=5)$. Scale bar, $50 \mu \mathrm{m}$. B, Immunoblots of CaMKII and CaMKII p-T286 phospho-epitopes in WT, mSCS, and treated mSCS TA muscles. "Values for CaMKII p-T286 are normalized to the level in WT muscle. The CaMKII p-T286 level is significantly reduced in mSCS muscle and control treated mSCS muscle, but partially restored $5 \mathrm{~d}$ after electroporation with CPST or Cdk5DN plasmids $(n=3)$. ${ }^{*} p<0.05$, Mann-Whitney $U$ test. C, Top: Cryosections of human muscle biopsies from normal, SCS, and CEAD patients showing immunostaining (green) for CaMKII (top) and CaMKII p-T286 (bottom). CaMKII colocalizes with NMJs in all sections. Immunostaining for CaMKII p-T286 is present in WT, but markedly reduced in SCS $(n=3)$ and CEAD $(n=4)$ muscles. Bottom: The fraction of CaMKII p-T286-labeled endplates in normal human $(n=3)$ was significantly greater than in human SCS $(n=3)$ and CEAD $(n=4)$ diseased muscle. "Normalized to CaMKII-stained endplates. Scale bar, $15 \mu \mathrm{m} .{ }^{* *} p<0.01$. D, Left: Immunoblots of CaMKII p-T286 phospho-epitope in HEK293 and C2C12 cell lines transiently coexpressing CaMKII plasmid with p25, Cdk5, and Cdk5DN plasmids. Transfected plasmids are indicated below. Right: Quantitation shows that in HEK293 and C2C12, the CaMKII p-T286 phospho-epitope level was increased in cells cotransfected with p25 and Cdk5DN plasmids, but was significantly less in cells cotransfected with p25 and Cdk5 plasmids. "Normalized to CaMKII plasmid-only transfection $(n=3)$. ${ }^{*} p<0.05$, Mann-Whitney U test.

(Fig. 3A, bottom). As expected, this treatment reduced calpain activity levels in mSCS muscle to the level of WT mice. Using voltage-clamp analysis of excised TA muscle $5 \mathrm{~d}$ after electroporation, we observed that transient expression of CPST had a pronounced effect on presynaptic transmitter release in neuromuscular transmission in both mSCS and WT muscle (Fig. 3B). In CPST-treated mSCS TA muscle, MEPC frequency increased $>2$-fold compared with the control plasmid-treated TA muscle $\left(1.38 \pm 0.13 \mathrm{~s}^{-1}\right.$ vs $0.67 \pm 0.07 \mathrm{~s}^{-1}$, respectively, $n=12, p<$ $0.05)$. QC was also increased by 2 -fold $(26.48 \pm 2.65$ vs $13.09 \pm$ 4.29 , respectively, $n=12, p<0.01$ ). This is similar to the findings with transgenic expression of CPST in skeletal muscle (Groshong et al., 2007). MEPC amplitudes, which are controlled predominantly by postsynaptic factors, were slightly decreased, as noted previously, presumably because of persistent activation of other proteases $(0.54 \pm 0.10 \mathrm{nA}$ vs $0.84 \pm 0.18 \mathrm{nA}$, respectively, $n=17$, $p<0.001$; Groshong et al., 2007). The net effect of these quantal changes was still a significant increase in EPC amplitudes $(15.98 \pm 2.76 \mathrm{nA}$ vs $10.33 \pm 2.2 \mathrm{nA}$, respectively, $n=12, p<$ 0.05 ; Fig. $3 B$ ). Furthermore, as we found with transgenic expression of CPST and inhibition of nNOS, acute inhibition of calpain had an equivalent effect on neuromuscular transmission in normal mice, increasing MEPC frequency $\left(1.64 \pm 0.12 \mathrm{~s}^{-1}\right.$ vs $1.18 \pm$ $0.09 \mathrm{~s}^{-1}$, respectively, $n=16, p<0.05$ ) and QC by $>2$-fold (44.74 \pm 3.66 vs $20.05 \pm 3.03 \mathrm{nA}$, respectively, $n=10, p<0.01$ ), with no effect on MEPC amplitude. In WT mice with acutely inhibited muscle calpain, EPCs were increased by $>2$-fold $(82.75 \pm 9.9 \mathrm{nA}$ vs $30.10 \pm 3.11 \mathrm{nA}$, respectively, $n=13, p<$ $0.001)$. This confirms our previous observations with transgenic expression of CPST that the activity of calpain within skeletal muscle negatively regulates synaptic strength through an effect on vesicular transmitter release in both physiological and pathological conditions.

Because calpain modulates the activity of Cdk 5 by cleavage of its coactivator, $\mathrm{p} 35$, to the constitutively active form as p 25 (Lee et al., 2000), we investigated whether the Cdk5 system is activated in mSCS. Figure $3 C$ shows that both the p 35 and p 25 forms are present in mSCS muscle, whereas there is no detectable p25 in WT muscle. Electroporation of CPST plasmid into mSCS muscle prevents the formation of p25 (Fig. 3C), which is consistent with inhibition of calpain (Fu et al., 2005). Cdk5 protein highly localized to the NMJ in WT and mSCS muscle (Fig. 3D, left) and its distribution was not affected by CPST expression (data not shown). However, we found that Cdk5 activity, measured using histone 1 as a substrate (Smith et al., 2006), was increased in mSCS muscle and normalized by inhibition of calpain through electroporation of CPST plasmid into muscle (Fig. 3D, top right). Overexpression of CPST in WT muscle reduced basal Cdk5 activity to $67 \%$ of the normal level ( $n=3, p<0.05$; Fig. $3 D$, bottom right).

Using voltage-clamp analysis of synaptic events in excised TA muscle, we investigated whether quantal release of ACh at the NMJ in mSCS or WT muscle was affected directly by Cdk 5 activity. Figure $3 E$ shows that direct inhibition of Cdk 5 in mSCS muscle by electroporation of a dominant-negative form of Cdk5 (Cdk5DN) $5 \mathrm{~d}$ previously increased MEPC frequency by nearly 2 -fold $\left(0.99 \pm 0.04 \mathrm{~s}^{-1}\right.$ vs $0.56 \pm 0.07 \mathrm{~s}^{-1}$, respectively, $n=8$, $p<0.001)$ and QC by 2 -fold $(23.52 \pm 3.7$ vs $11.46 \pm 2.94$, respectively, $n=10, p<0.05)$, to nearly normal levels, with a resultant increase in EPCs $(30.38 \pm 3.81 \mathrm{nA}$ vs $11.23 \pm 3.5 \mathrm{nA}$, respectively, $n=10, p<0.01)$. Interestingly, Cdk5DN had similar effects on neuromuscular transmission in normal mice, in- 

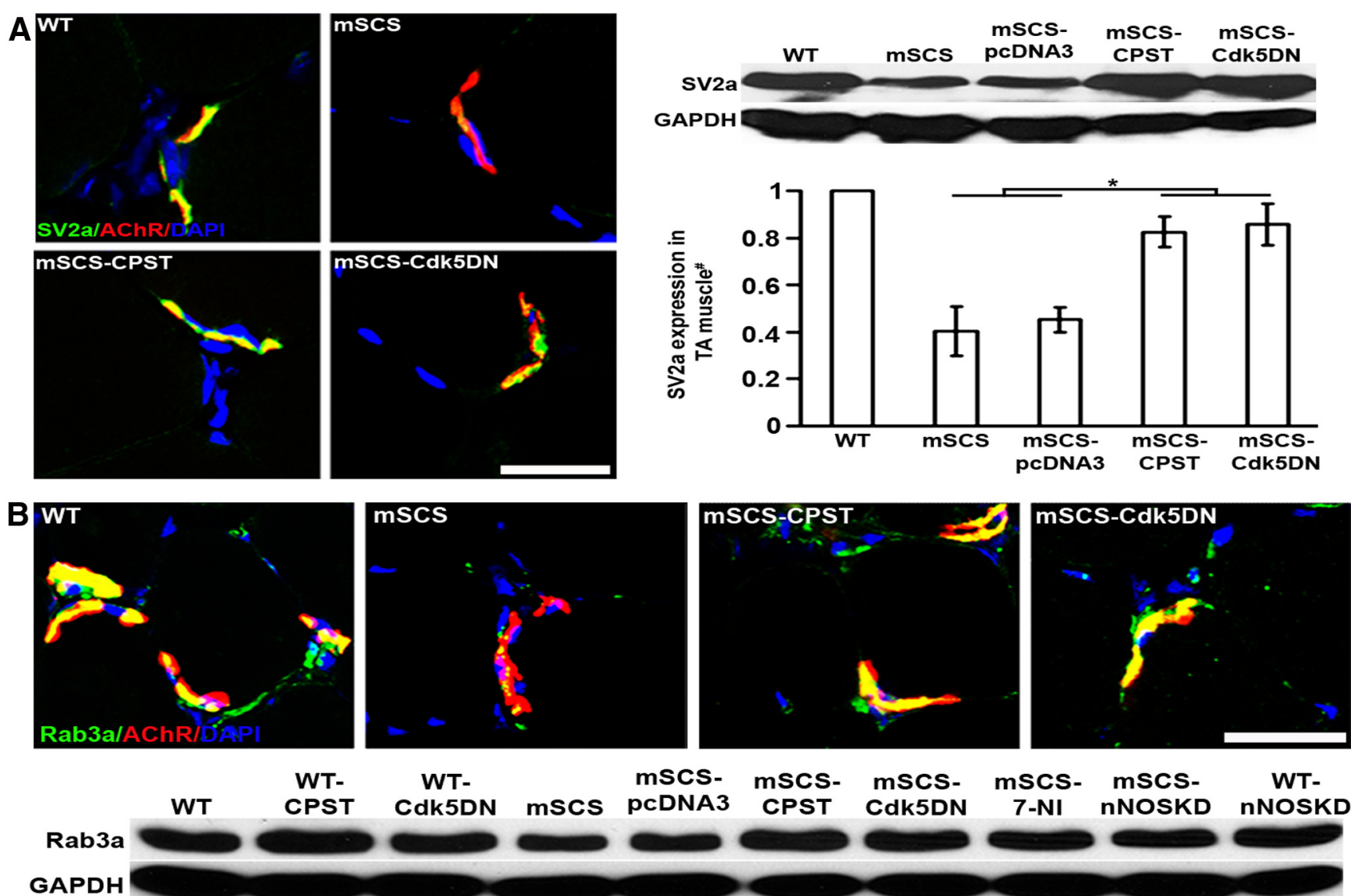

WT-

mscs.

Cdk5DN mSCS pcDNA3
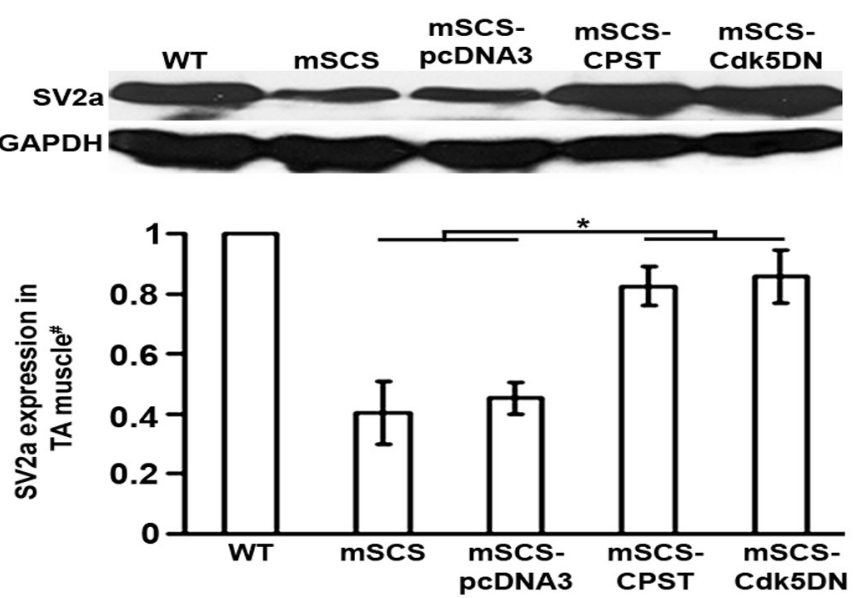

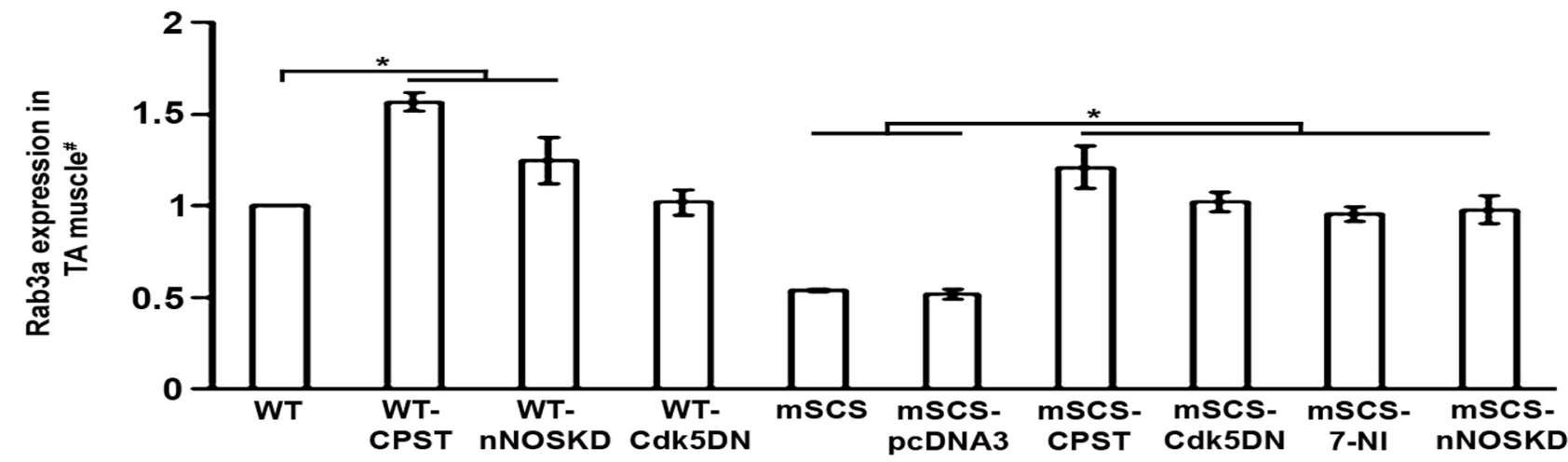

C
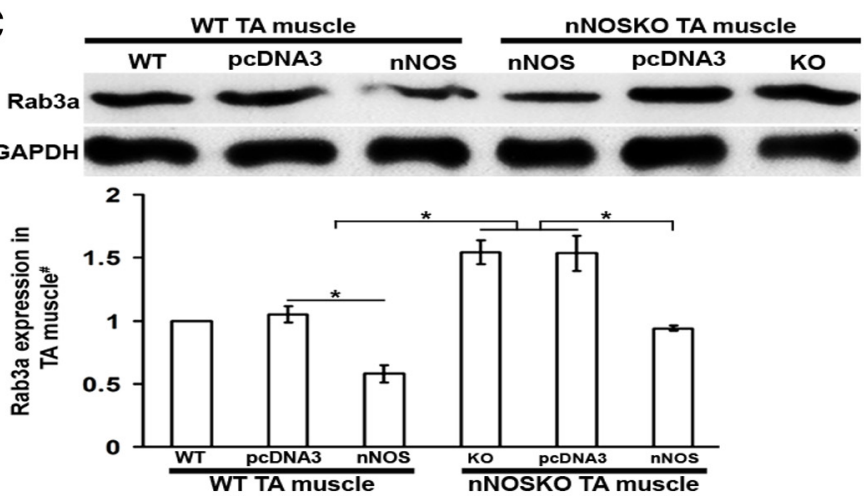

D
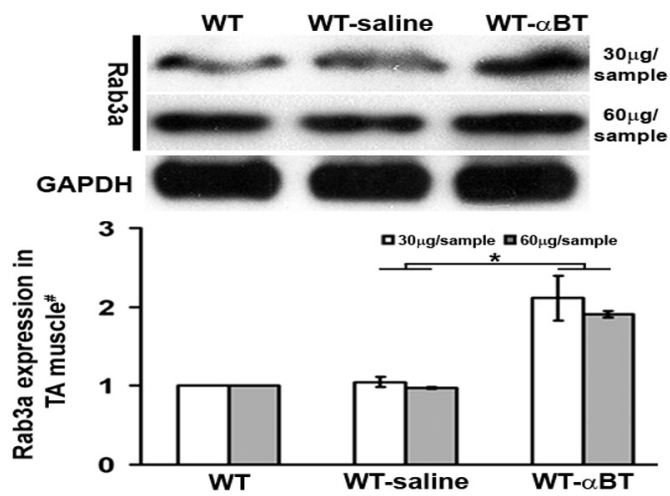

Figure 6. The activity-related, calpain-Cdk5-nNOS pathway modulates vesicle protein expression in skeletal muscle. $A$, Left: Cryosections of WT and mSCS muscle immunostained for SV2a protein (green) and NMJ (TxR- $\alpha$ BT, red) show that SV2a is colocalized with NMJ in WT muscle, but markedly reduced in mSCS muscle. Treatment of TA by electroporation with CPST or Cdk5DN $5 \mathrm{~d}$ previously caused a notable increase in SV2a immunolocalization at NMJ. Right: Immunoblots (top) of SV2a protein in homogenates of TA muscle from WT, mSCS, or pretreated mSCS. Quantitation (bottom) shows that SV2a was reduced in mSCS and mSCS treated with control pCDNA3 plasmid relative to WT, but SV2a levels in mSCS treated with CPST or Cdk5DN were significantly increased ( $n=3$ ). ${ }^{\#}$ Normalized to WT. Scale bar, $15 \mu \mathrm{m} .{ }^{*} p<0.05$. B. Top: Cryosections of WT and mSCS muscle immunostained for Rab3a protein (green) and NMJ (TxR- $\alpha$ BT, red) (Figure legend continues.) 
creasing MEPC frequency nearly 2-fold $\left(2.28 \pm 0.33 \mathrm{~s}^{-1}\right.$ vs $1.20 \pm 0.12 \mathrm{~s}^{-1}$, respectively, $\left.n=10, p<0.05\right)$ and significantly increasing QC (27.02 \pm 2.07 vs $19.76 \pm 1.51$, respectively, $n=8$, $p<0.01)$. This suggests that, like NO and calpain, postsynaptic Cdk5 activity plays a role in modulating synaptic transmission in normal mice. These findings are similar to previous studies in which $\mathrm{Cdk} 5^{-l-}$ mice showed increased quantal release (Fu et al., 2005). In the present study, however, Cdk5 or calpain were inhibited only in muscle and apparently exerted a retrograde effect on presynaptic function. These studies suggest that muscle calpain activity negatively regulates ACh release through its effect on muscle Cdk5 activity. Interestingly, in both mSCS and WT mice, MEPC amplitudes were also increased by $\sim 40 \%$, suggesting that Cdk5 activity also influences postsynaptic factors, perhaps through an effect on AChR gene expression. Our findings suggest that calpain modulates quantal release through a $\mathrm{Cdk} 5$ pathway in normal and mSCS muscles.

\section{The calpain/Cdk5 pathway modulates nNOS activity through CaMKII in normal and mSCS muscles}

To investigate the correlation between increased calpain and Cdk5 activities and NO production in mSCS muscle, we examined the nNOS system in mSCS muscle treated by electroporation of CPST or Cdk5DN plasmids. Figure $4 A$ shows that inhibition of calpain or Cdk5 locally in mSCS TA muscle by expressing CPST or Cdk5DN reverses phospho-nNOS ratios of p-S847 and p-S1412 at the NMJ to the proportions similar to those of WT mice, with greater numbers of NMJs showing labeling for $\mathrm{p}-\mathrm{S} 847$, the inhibitory nNOS marker, than $\mathrm{p}-\mathrm{S} 1412$, the activated nNOS marker, in treated mice compared with control plasmid-treated mice $(p<0.001)$. Similarly, after inhibition of either calpain or Cdk5, the number of NMJs labeled with cGMP antibody was reduced to WT levels. In mSCS muscle homogenates, the levels of p-S847 nNOS were significantly increased, whereas p-S1412 nNOS levels were decreased by inhibition of calpain or Cdk5 ( $p<0.05$; Fig. $4 B$ ). Finally, NMJ-localized nNOS activity (Fig. $4 C$, top) and the relative levels of nNOS in muscle homogenates (Fig. 4C, bottom) were decreased by local inhibition of either calpain or Cdk5. Electroporation of control plasmid, pcDNA3, had no effect on nNOS activity markers in these experiments. These results suggest that the retrograde effect of

\footnotetext{
$\leftarrow$

(Figure legend continued.) show that Rab3a is colocalized with NMJ in WT muscle, but markedly reduced in $\mathrm{mSCS}$ muscle. Treatment of TA by electroporation with CPST or Cdk5DN for $5 \mathrm{~d}$ previously caused a marked increase in Rab3a immunolocalization at NMJ. Bottom: Immunoblots of Rab3a protein in homogenates of TA muscle from WT, mSCS, or pretreated WT or mSCS. Quantitation shows that Rab3a level was reduced in $\mathrm{mSCS}$ and $\mathrm{mSCS}$ treated with control pcDNA3 plasmid relative to WT, but Rab3a levels in mSCS treated with CPST or Cdk5DN, as well as siRNA for nNOS KD and the nNOS inhibitor 7-NI were significantly increased. "Normalized to WT $(n=3)$. Scale bar, $15 \mu \mathrm{m} .{ }^{*} p<0.05$. Treatment of WT muscle with CPST and siRNA to nNOS KD also significantly increased Rab3a expression relative to WT. Electroporation of Cdk5DN in WT TA muscle had no effect on Rab3a expression $(n=3)$. Scale bar, $15 \mu \mathrm{m} .{ }^{*} p<$ 0.05. C, Immunoblots (top) of Rab3a protein in homogenates of TA muscle from WT and nNOS KO muscle after treatment with control plasmid or with nNOS expression plasmid. Quantitation (bottom) shows that the Rab3a protein level was higher in nNOS KO TA muscle compared with WT. Five days after electroporation of nNOS plasmid into nNOS K0, the Rab3a level was significantly reduced relative to that of nNOS KO. After expression of nNOS in WT muscle, the level of Rab3a was significantly less than in WT levels. "Normalized to WT $(n=3) .{ }^{*} p<0.05$. D, Immunoblots (top) of Rab3a protein in homogenates of TA muscle from untreated WT and after systemic treatment saline or $\alpha \mathrm{BT}$. Thirty and $60 \mu \mathrm{g}$ of sample were loaded into separate gels. Quantification (bottom) shows that saline treatment did not affect Rab3a protein level, but pretreatment with $\alpha$ BT led to a significant increase in Rab3a level $(n=3) .{ }^{~ " N o r m a l i z e d ~ t o ~ W T . ~}$ ${ }^{* *} p<0.05$, Mann-Whitney $U$ test.
}

NO on motor nerve quantal activity is mediated through a calpain-Cdk5 pathway.

Regulation of nNOS activity can be attributed in part to inhibitory phosphorylation of nNOS at S847 by CaMKII (Hayashi et al., 1999). To test whether increased calpain and Cdk5 activities were associated with a reduction in CaMKII-mediated nNOS phosphorylation in the NMJ, we examined cryosections and homogenates of TA muscle treated as shown in Figure 4 by electroporation with CPST or Cdk5DN vectors or with control plasmid to determine the expression level of the activated form of CaMKII, autophosphorylated at Thr-286 (p-T286 CaMKII), relative to total CaMKII. Immunostaining for CaMKII protein highly localized to WT mouse NMJs, as shown previously (MartinezPena y Valenzuela et al., 2010), as well as at mSCS NMJs, and was not altered by expression of CPST or Cdk5DN (Fig. 5A, left). However, using antibody to p-T286 CaMKII, we found that no NMJs from untreated SCS mice had detectable p-T286 CaMKII labeling compared with extensive p-T286 labeling in WT mice. Treatment of mSCS TA muscle with CPST or Cdk5DN increased the NMJ labeling for p-T286 CaMKII compared with the effect of control plasmid (Fig. $5 A$, right).

In TA muscle homogenates, total CaMKII protein levels were no different in WT, mSCS, and treated mSCS muscle (Fig. 5B). However, using the phospho-epitope-specific antibody to p-T286 CaMKII, the amount of p-T286 CaMKII in mSCS muscle was approximately 3 -fold less than in WT muscle, as indicated by the plotted ratios of p-T286 CaMKII to total CaMKII $(p<0.05$; Fig. $5 B)$. Moreover, expression of CPST or Cdk5DN in mSCS TA muscle by electroporation of plasmid vectors increased p-T286 CaMKII to levels slightly higher than in WT, presumably correcting CaMKII activity in mSCS muscle (Fig. 5B). This change would have the predicted effect of increasing phosphorylation of nNOS at S847 and reducing NOS activity at the NMJ, as shown in Figure 1. These studies suggest that increased activities of calpain and $\mathrm{Cdk} 5$ are responsible for the reduced activity of CaMKII in mSCS muscle, the resultant reduced numbers of p-S847 nNOS-labeled versus p-S1412 nNOS-labeled NMJs, and the increased NO production at NMJs in mSCS muscle.

To look for a similar pattern of CaMKII labeling in the SCS and CEAD biopsies shown in Figure $1 A$, we used specific antibodies to CaMKII and p-T286 CaMKII to determine the fraction of endplates labeled in each disorder. Figure $5 C$ shows that p-T286 CaMKII is localized to human NMJs and more readily detectable in normal human muscle compared with SCS and CEAD biopsies. We found that $48 \pm 6 \%$ of endplates labeled for p-T286 CaMKII in normal human muscle, nearly 2 -fold over that seen in human SCS $(27 \pm 7 \%, p<0.001)$ and CEAD muscle $(24 \pm 8, p<0.001)$. These findings suggest that a reduced activation of CaMKII in SCS and CEAD muscle might underlie the changes in nNOS activity seen in these diseases.

The inhibitory effect of Cdk5 on CaMKII phosphorylation may be facilitated by the fact that Cdk5 coactivators p 35 and p39 interact with CaMKII and that $\mathrm{Cdk} 5$ phosphorylates protein phosphatase-1, which is known to dephosphorylate CaMKII (Bradshaw et al., 2003). To test for an effect of Cdk5 activity on CaMKII in a cellular model, we transiently overexpressed CaMKII in HEK293 and C2C12 myoblast cells in the presence of control plasmid or the plasmids expressing Cdk5, Cdk5DN, and p25. Figure $5 D$ shows that expression of p25 alone or Cdk5 with p25 significantly decreased p-T286 CaMKII expression, whereas coexpression of Cdk5DN with p25 increased p-T286 CaMKII expression. These findings indicate that CaMKII autophosphorylation is influenced by the activity of Cdk5, presumably by an effect on an intermediate regulatory enzyme, suggesting an 

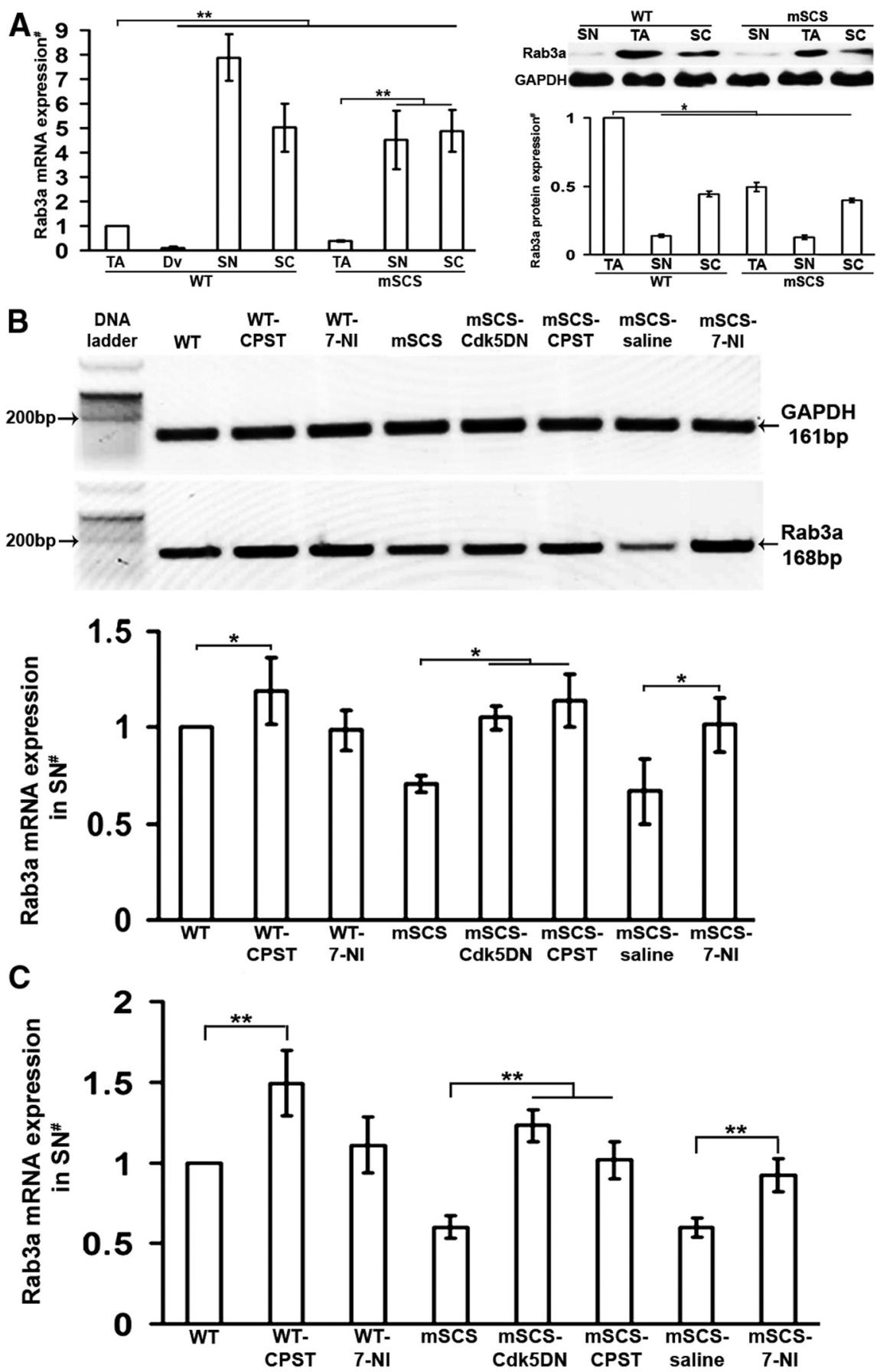

Figure 7. The calpain-Cdk5-nNOS pathway influences Rab3a mRNA expression in SN. $\boldsymbol{A}$, Left: Rab3a mRNA levels in TA muscle (TA), 3-d-denervated TA muscle (Dv), SN, and SC of WT and mSCS mice. \#Normalized to untreated WT TA muscle. After $3 \mathrm{~d}$ denervation, the Rab3a mRNA level in denervated WT TA muscle (WT-Dv) was significantly reduced. In WT or mSCS mice, the Rab3a mRNA level was higher in SN and SC but lower in TA $(n=5)$. ${ }^{* *} p<0.01$. Right: Immunoblots (top) of Rab3a protein from homogenates of TA, SN, and SC. Quantification (bottom) in the WT or mSCS mice showed that the relative Rab3a protein level in SN and SC was significantly lower in SN and SC than in TA, "Normalized to untreated WT TA muscle $(n=3) .{ }^{*} p<0.05$, MannWhitney $U$ test. $\boldsymbol{B}$, Top: Rab3a mRNA levels in SN by semi-qRT-PCR. Rab3a PCR product (168 bp) was amplified from SN in WT or mSCS mice with different treatments. Bottom: "Values expressed as a ratio of GAPDH signal normalized to untreated WT SN. CPST increased Rab3a mRNA in both WT and mSCS. Cdk5DN and the nNOS inhibitor 7-NI increased Rab3a in mSCS. 7-NI had no effect on WT. Saline had no effect in mSCS $(n=5)$. ${ }^{*} p<0.05$. C, Measurement of Rab3a mRNA level in SN by $q R T-P C R$ showed similar results as in $\boldsymbol{B}$. "Normalized to untreated WT SN $(n=5) .{ }^{* *} p<0.01$, Mann-Whitney U test.

additional potential regulatory pathway for CaMKII in the NMJ. These findings strongly suggest that a calpain/Cdk5/CaMKII pathway modulates quantal release through the nNOS-NO pathway at NMJ.
The calpain/Cdk5/nNOS pathway modulates presynaptic expression of synaptic vesicle proteins in normal and SCS muscles

To look for structural correlates for the calpain-nNOS-dependent regulation of quantal activity, we measured the changes in expression of the presynaptic proteins SV2 and Rab3a by immunolocalization and immunoblotting (Fig. 6A,B). Rab3a is involved in exocytosis by regulating a late step in synaptic vesicle fusion through an effect on membrane flow in the nerve terminal (Matteoli et al., 1991). SV2 is a synaptic vesicle protein that interacts with synaptotagmin (Janz et al., 1999). Both SV2 (Fig. 6A, left) and Rab3a (Fig. 6B, top) showed strong colocalization with $\alpha \mathrm{BT}$ labeling at NMJ in WT muscle and severely reduced expression at NMJ in untreated mouse mSCS muscle. However, after electroporation of mSCS muscle with CPST or Cdk5DN plasmids, expression of both SV2 and Rab3a at the NMJ was restored, consistent with the effect of expression of CPST and Cdk5DN on restoration of quantal activity in mSCS muscle. Similarly, in homogenates of TA muscle protein, the levels of both SV2 (Fig. 6A, right) and Rab3a (Fig. 6B, bottom) were reduced in SCS mice compared with WT. Expression of CPST and Cdk5DN increased the SV2 and Rab3a protein levels in mSCS TA muscle compared with control. Treatment of mSCS muscle either by siRNA-mediated nNOS KD in TA muscle or by intraperitoneal injection with 7-NI, a relatively specific nNOS inhibitor, increased Rab3a levels (Fig. 6B). CPST, nNOS KD, and 7-NI also increased Rab3a in WT muscle, although the modest increase after Cdk5DN treatment was not significant. Figure $6 \mathrm{C}$ shows that Rab3a level in $\mathrm{nNOS} \mathrm{KO}$ TA muscle was increased 1.5-fold over WT. Electroporation of nNOS plasmid into nNOS KO TA muscle reduced Rab3a protein to WT levels. Electroporation of nNOS plasmid into WT TA muscle reduced the Rab3a level to $50 \%$ of WT. Reduced presynaptic Rab3a protein levels in mSCS mice are attributable to increased cholinergic activity. Also, cholinergic blockade is known to lead to increased presynaptic function. Therefore, we investigated whether blockade of cholinergic activity at the NMJ altered Rab3a expression in muscle. Seven days after intraperitoneal administration of $\alpha \mathrm{BT}$ to WT mice, we found that Rab3a expression levels in TA muscles were 2 -fold greater than in saline-treated controls $(p<0.05$; Fig. 6D). These findings suggest that the calpain-Cdk5DN-nNOS pathway provides retrograde feedback from changes in cholinergic input by in- 
A
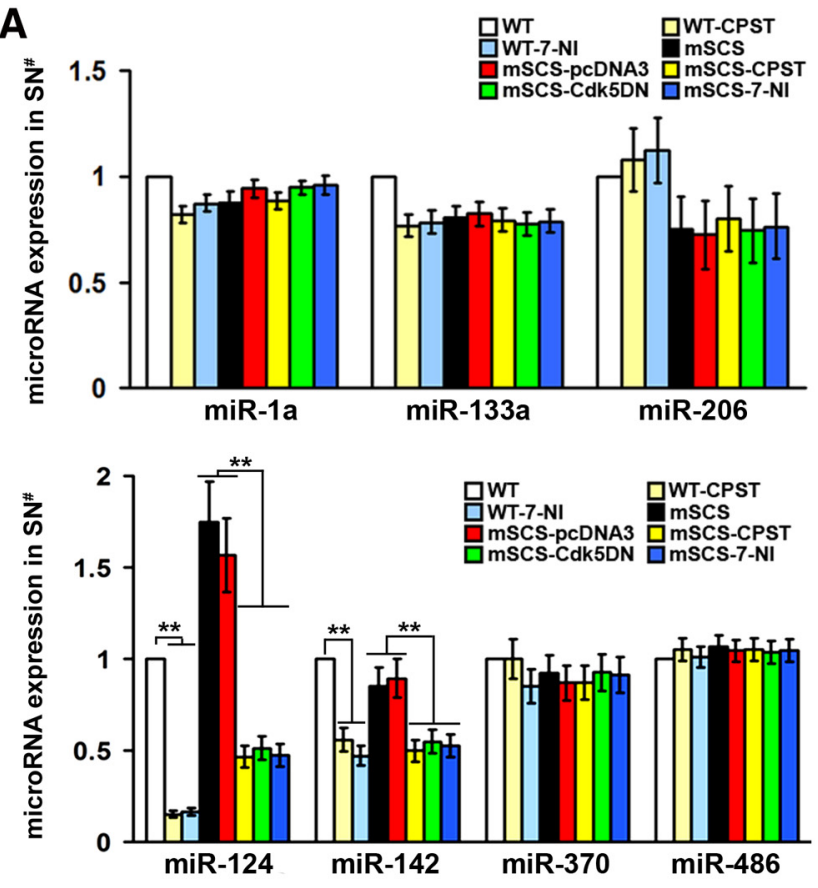
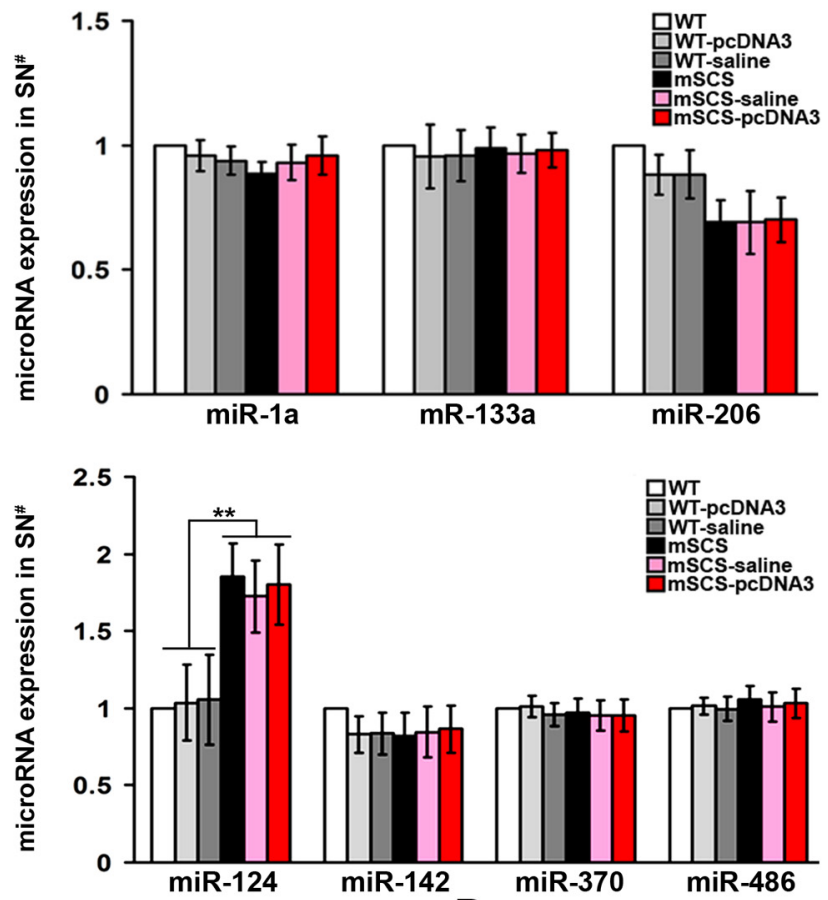

B

C
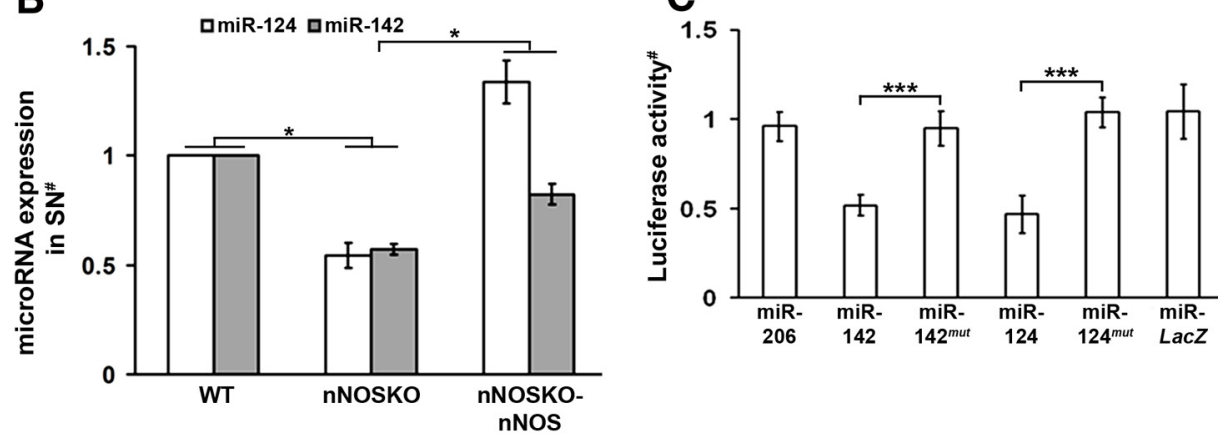

D

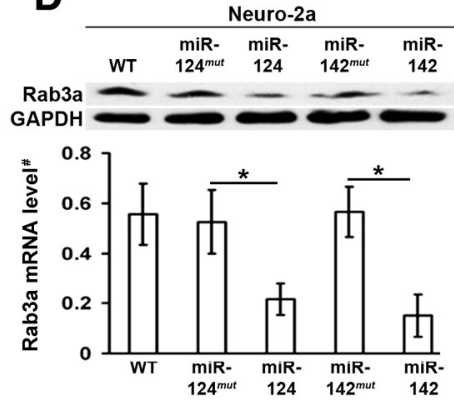

Figure 8. Calpain-Cdk5-nNOS pathway modulates Rab3a expression through miR-124 and 142 in SN. A, Expression levels of seven miRNAs in WT and mSCS SN with different treatments measured by qRT-PCR. Top: miR-1a, miR-133a, and miR-206 expression levels in WT, mSCS, and treated mSCS mice. The levels of miR-1, miR-133a, and miR-206 in SN showed no significant differences between WT and mSCS mice or before and after treatments. Bottom: miR-124, miR-142, miR-370, and miR-486 expression levels in WT, SCS, and treated SCS mice. The miR-124 expression level in SN was significantly higher in mSCS than in WT mice. Treatment of mSCS TA by electroporation of CPST or Cdk5DN expression plasmids or by systemic administration of 7-NI caused a significant reduction of miR-124 levels. Treatment of WT mouse TA with CPST expression plasmid or by systemic administration of 7-NI caused a significant reduction of miR-124 levels. Treatment of mSCS or WT TA with pcDNA3 or with saline injection had no effect on miR-124 expression. Levels of miR-142 expression were no different between WT and mSCS mice. However, inhibition of the calpain-Cdk5-nNOS pathway in mSCS had similar effects on miR-142. Treatment of mSCS mouse TA by electroporation of CPST or Cdk5DN expression plasmids or by systemic administration of 7-NI caused a significant reduction of miR-142 levels. Treatment of WT mouse TA with CPST expression plasmid or by systemic administration of 7-NI caused a significant reduction of miR-142 levels. Treatment of mSCS or WT TA with pcDNA3 or with saline injection had no effect on miR-142 expression. "Normalized to untreated WT SN $(n=5) .{ }^{* *} p<0.01$, Mann-Whitney $U$ test. $\boldsymbol{B}$, miR-124 and miR-142 expression levels in SN in WT, nNOS KO, and nNOS KO mice treated by electroporation of nNOS in TA 5 d previously. "Normalized to untreated WT SN. Expression levels of both miR-124 and miR-142 in SN were significantly lower in nNOS KO mouse than in WT mouse SN. Expression of nNOS in nNOS KO TA muscle significantly increased the levels of miR-124 and miR-142 expression $(n=3) .{ }^{*} p<0.05$, Mann-Whitney $U$ test. C, Rab3a 3'-UTR-directed luciferase activity reveals modulation by miR-124 and miRNA-142, but not their mutant variants. A luciferase expression construct bearing Rab3a 3' -UTR was coexpressed with expression plasmids for miRNAs. Coexpression of both miR-124 and miR-142 caused significant reduction of luciferase activity. Coexpression of miR-124 ${ }^{\text {mut }}$ or miR-142 ${ }^{\text {mut }}$ or the controls, miR-206 and miR-LacZ, had no effect on luciferase activity $(n=10)$. " Normalized to luciferase activity of Rab3a $3^{\prime}$-UTR only transfection. ${ }^{* * *} p<$ 0.001 , Student's $t$ test. $\boldsymbol{D}$, miRNA modulation of endogenous expression of Rab3a. miR-124, miR-124 ${ }^{\text {mut }}$, miR-142, and miR-142 ${ }^{\text {mut }}$ were transfected separately in the neuroblastoma cell line Neuro-2a, which expresses Rab3a. Expression levels of Rab3a protein in each culture were compared by immunoblot (top) after $5 \mathrm{~d}$. Rab3a protein levels (bottom) were significantly reduced in Neuro-2a cells transfected with miR-124 or miR-142 compared with untreated Rab3a protein level. Mutant miRNAs, miR-124 ${ }^{\text {mut }}$, or miR-142 ${ }^{\text {mut }}$ had no effect. ${ }^{*}$ Normalized to GAPDH ( $n=3$ ). ${ }^{*} p<$ 0.05 , Mann-Whitney U test.

fluencing structural components of vesicular transmitter release and function of the innervating motor nerve.

The Rab3a detected in muscle presumably originates from the intramuscular peripheral nerves. To confirm this, we used qRT-PCR to compare Rab3a mRNA levels in normal TA muscle and denervated TA muscle. The Rab3a mRNA level in 3 -day denervated muscle was reduced to $10 \%$ of normal muscle, which confirmed its neural origin (Fig. 7A, left). Rab3a mRNA was also more abundant in the SN and muscle of WT mice compared with mSCS muscle, although there were no differences between WT and mSCS in SC. To investigate whether the changes of Rab3a at mRNA level were accompanied by alterations at the protein level, we compared the Rab3a protein expression in TA muscle, SN, and SC in WT and SCS mice. We found that relative expression of Rab3a protein (vs GAPDH) in the TA muscle in both WT and SCS mice was $\sim 2$-fold higher than in SC and 7-fold higher than in SN (Fig. $7 A$, right). Consistent with the changes in Rab3a mRNA in 


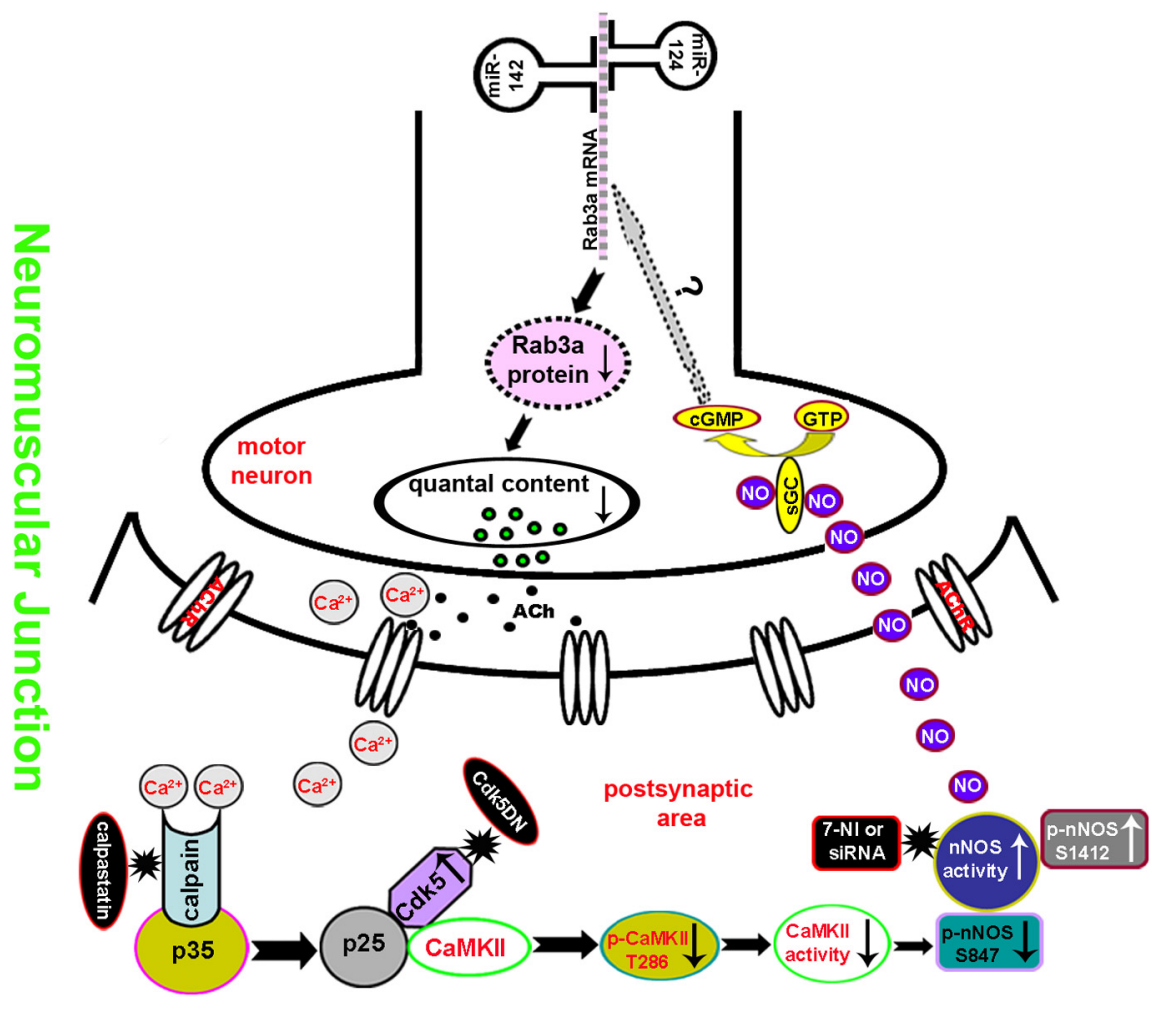

Figure 9. Summary schema of the calpain-Cdk5-nNOS retrograde pathway in NMJ illustrating that in SCS diseased muscle, mutant AChR-mediated $\mathrm{Ca}^{2+}$ overload activate calpain and amplify Cdk5 activity via calpain-dependent cleavage of p35 to p25. Increased Cdk5 activity reduces CaMKII activity by decreasing CaMKII phosphorylation at Thr286. Decreased CaMKII activity reduces the ratio of nNOS phosphorylation at Ser 847 to Ser 1412, which finally amplifies N0 production in SCS muscle. More N0 arrival at motor neurons increases the GGMP level, which is likely responsible for increased miRNA 124 and miRNA 142 expression that directly reduces the Rab3a mRNA level and protein production in motor neuron terminals. Decreased Rab3a expression influences QC release at the endplate; however, inhibition of calpain-Cdk5-nNOS pathway by CPST, Cdk5DN, or 7-NI recoveres Rab3a expression and improves quantal release at motor neuron terminals.

muscle, the Rab3a protein level in mSCS TA muscle was significantly lower than in WT TA muscle. Interestingly, Rab3a protein levels in SN and SC showed no difference between WT and SCS mice. These results suggest that the differences in Rab3a protein levels between mSCS and WT muscles result from gene products arising from motor nerves, as opposed to either cross-reacting proteins or aberrant muscle transcripts. More importantly, these findings are consistent with the view that reduced Rab3a in SCS mice results from an effect on mRNA stability and protein synthesis limited to the nerve terminus. Finally, we investigated whether the changes in the calpain-nNOS pathway that influence neuromuscular transmission presynaptically in mSCS and WT muscle act through an effect on Rab3a mRNA levels in SN. Figure $7 B$ shows that there are significant differences in the abundance of a $168 \mathrm{bp}$ amplimer corresponding to Rab3a after the pretreatments that modulate the calpain-Cdk5-nNOS pathway (as shown in Fig. 7C), as compared by semi-qRT-PCR and qRT-PCR. In mSCS muscle, CPST, Cdk5DN, and 7-NI significantly increased Rab3a mRNA levels, whereas pcDNA3 and saline injection had no effect. Expression of CPST in WT muscle significantly increased Rab3a mRNA levels. The increase after 7-NI treatment was not statistically significant. These results suggest that calpain, Cdk5, and nNOS activities in skeletal muscle negatively regulate presynaptic quantal activity through an effect on the mRNA levels of at least one presynaptic protein, Rab3a.
Neural miRNAs control calpain/Cdk5/ nNOS-dependent alterations in synaptic vesicle protein levels in normal and $\mathrm{mSCS}$ muscles

Changes in Rab3a mRNA levels in peripheral nerve without changes in SC (Fig. 7A) suggest that the SCS mice have altered mRNA stability within peripheral nerve, which may be modulated in WT and SCS mice through the calpain-Cdk5-nNOS pathway. miRNAs, small, noncoding RNA segments (20-24 bp) function by binding with 3 '-UTR of target mRNA, reducing mRNA stability, leading to mRNA degradation (Nielsen et al., 2009). miRNAmediated mRNA and protein changes have been widely reported in injured SN and SC studies (Strickland et al., 2011; Yu et al., 2011) and in presynaptic and postsynaptic regulation of homeostatic synaptic plasticity in the CNS (Cohen et al., 2011). To test for a possible miRNA-mediated mechanism, we selected seven candidate miRNAs using the following rationale: $\mathrm{miR}-1 \mathrm{a}, \mathrm{miR}-133 \mathrm{a}$, and miR-206 principally regulate muscle differentiation and are expressed in both murine skeletal muscle and neural tissue (Chen et al., 2006; Kim et al., 2006; Bak et al., 2008). miR-124, miR-142, miR-370, and miR-486 are primarily identified in murine neural tissue (Bak et al., 2008) and are predicted to act on Rab3a 3'-UTR based on miRNAspecified target-finding engine (GriffithsJones et al., 2006; Kozomara and GriffithsJones, 2011).

We used qRT-PCR to investigate whether the levels of any of these miRNAs are affected in WT or SCS mice. Figure $8 A$ shows the relative miRNA expression levels of the seven miRNAs in SN. Of the muscle-specific miRNAs, miR-1, miR-133a, and miR-206 (Fig. $8 A$, top), only miR-206 was significantly reduced in mSCS SN (to $75 \%$ of WT, $p<0.01$ ). However, miR-206 was not increased by CPST, Cdk5DN, 7-NI, or control treatments in either mSCS or WT mice. In contrast, of the four predicted nerve-specific miRNAs, miR-124, miR-142, miR-370, and miR-486 (Fig. 8A, bottom), only miR-124 was significantly increased in mSCS SN compared with WT SN (nearly 2 -fold, $p<0.01$ ). Pretreatment of SCS mice by electroporation of CPST or Cdk5DN reduced the miR-124 level to $47 \%$ and $51 \%$ of WT, respectively, whereas no change was found in control plasmid (mSCS-pcDNA3, 1.6-fold, $p<0.01$ ). Pretreatment of SCS mice with 7-NI reduced the miR124 level in SN to $46 \%$ of WT, whereas no change was identified in saline control treatment $(1.7$-fold; $\mathrm{p}<0.01)$. Pretreatment of WT mice with CPST reduced miR-124 level to $15 \%$ of untreated WT, whereas treatment with 7-NI reduced miR-124 to $17 \%$ of WT SN $(p<0.01)$. Moreover, the miR-124 level in SN of nNOS KO mice was reduced to $53 \%$ of WT, whereas electroporation of nNOS plasmid to nNOS KO mice increased the miR-124 level in SN 1.3-fold over WT. Reduced expression of miR-124 in SN was correlated closely with the increase of Rab3a expression and the increased quantal activity in WT and mSCS muscle pretreated with CPST, Cdk5DN, or siRNA for nNOS. Interestingly, although the level of miR-142 expression was no different between 
WT and mSCS SN, miR-142 showed effects similar to those of miR-124 in SN after these same pretreatments to mSCS and WT TA muscle. Furthermore, the level of miR-142 in SN of nNOS KO was reduced to $54 \%$ of WT $(p<0.05)$, whereas electroporation of nNOS plasmid to nNOS KO mice increased the miR-142 level in $\mathrm{SN}$ to $82 \%$ of WT $(p<0.05$; Fig. $8 B$ ). There were no differences in the levels of the other miRNAs in untreated or pretreated WT and SCS mice.

Finally, to test for a direct interaction of miR-124, miR-142, and miR-206 with the Rab3a 3'-UTR, we cotransfected each miRNA separately with a luciferase-based miRNA reporter containing 3' -UTR-Rab3a in HEK293 and measured luciferase activity (Greco and Rameshwar, 2007). Both miR-124 and miR-142 significantly reduced the relative luciferase activity to $0.47 \pm 0.11$ and $0.52 \pm 0.06$ of the original value, respectively, in cells expressing miRNA reporter bearing a $3^{\prime}$-UTR-Rab3a $(n=10, p<0.001$; Fig. 8C). Conversely, when cells were cotransfected with reporter constructs bearing mutant miR-124 (miR-124 ${ }^{\text {mut }}$ ) and mutant miR-142 (miR-142 ${ }^{\text {mut }}$ ) (see Materials and Methods for sequences) in place of WT reporters, luciferase levels were not changed (1.04 \pm 0.09 and $0.95 \pm 0.10$ of control, respectively, $p>0.98$; Fig. $8 C$ ). miR-206 did not influence luciferase activity of $3^{\prime}$-UTR-Rab3a $(0.96 \pm 0.08, p>0.98$; Fig. $8 C)$. miRNA targeted to the $\beta$-galactosidase $3^{\prime}$-UTR had no effect on luciferase activity of $3^{\prime}$-UTR-Rab3a $(1.04 \pm 0.13, p>0.98)$.

To investigate the role of miRNA in the modulation of endogenous levels of Rab3a, we used the neuroblastoma cell line neuro-2a (Nishimura et al., 1995). After a $5 \mathrm{~d}$ transfection of neuro-2a with the plasmids that express miR-124 and miR-142, Rab3a protein was significantly reduced relative to GAPDH $(0.56 \pm 0.12$, untransfected, vs $0.15 \pm 0.08$, miR-142, and $0.22 \pm$ 0.06, miR-124, $p<0.05$; Fig. 8D). However, expression of the mutant forms of miR-124 and miR-142 in neuro-2a cells had no effect on Rab3a protein expression $\left(0.53 \pm 0.13, \mathrm{miR}-124^{\mathrm{mut}}\right.$ and $0.56 \pm 0.1$, miR-142 ${ }^{\text {mut }}, p>0.97$; Fig. $8 D$ ). These results suggest that muscle activities of calpain, Cdk5, and nNOS influence presynaptic quantal release through miRNA-based modulation of Rab3a mRNA stability that controls Rab3a expression levels.

\section{Discussion}

In this study, we have shown that muscle calpain activity plays a prominent role as an upstream trigger to couple increases in junctional sarcoplasmic $\mathrm{Ca}^{2+}$ levels to modulation of muscle nNOS activity and presynaptic neurotransmitter release through an miRNA mechanism. This feedback mechanism, which proceeds through a protein kinase cascade, appears to be present both in normal and pathological states. Figure 9 summarizes the steps underlying this nNOS feedback pathway in the NMJ.

Calpain is a cysteine protease whose substrates include several cytoskeletal proteins and signaling molecules, such as Cdk5 p35 coactivator (Lee et al., 2000). Calpain plays roles in cell cycle, cell migration and adhesion, axon guidance, NMJ formation, and synaptic plasticity (Robles et al., 2003; Jánossy et al., 2004; Perrin et al., 2006; Chen et al., 2007; Zadran et al., 2010) and has been strongly implicated in numerous cell death pathways. However, until this study, its perceived role in synaptic plasticity has been limited to influencing synaptic strength directly within the cell in which is activated. It has not been shown previously to act through CaMKII and nNOS to exert a retrograde effect on synaptic transmission potentially underlying homeostatic synaptic plasticity, nor in contributing to presynaptic depression in neuromuscular disease. Its role in degradation in the NMJ appears to be of secondary importance (Groshong et al., 2007). These obser- vations may provide insights into new avenues for therapy for these disorders. If this pathway can be identified in CNS synapses, it could provide new insights into synaptic plasticity, learning, and memory.

Cdk5 is a proline-directed serine/threonine kinase that has numerous identified protein substrates in the CNS and in nonneuronal cells. It plays a central role in CNS development, function and disease, and is involved in a wide array of physiological processes, including neuronal migration, axon guidance, synaptic transmission, endocytosis, and synaptic plasticity (Nguyen and Bibb, 2003; Hirasawa et al., 2004; Hawasli et al., 2007; Poore et al., 2010). Until now, Cdk5 was only known to influence cellular behavior within its cell of origin (Nguyen and Bibb, 2003; Evans and Cousin, 2007). Beyond coupling Cdk5 activation to synaptic activity through calpain, this study broadens the scope of influence of Cdk5 to include a retrograde effect on the presynaptic neuron through its effect on NO production. This finding may have significant physiological and therapeutic implications, particularly if a comparable role can be identified in CNS synapses.

The role of NO generated by nNOS in neuromuscular transmission has been controversial, with some studies demonstrating enhancement and others suggesting suppression of transmitter release (Etherington and Everett, 2004; Nickels et al., 2007). Several studies have already suggested that NO, mediates a form of retrograde feedback in synaptic transmission (Lindgren and Laird, 1994; Wang et al., 1995; Etherington and Everett, 2004; Graves et al., 2004). The present study characterizes a pathway by which synaptic nNOS can be activated through excessive cholinergic activity after calpain activation and further implicates $\mathrm{NO}$ as a source of negative feedback. This study also suggests that nNOS activity plays a significant role in modulating synaptic strength in clinical disease. Excessive NO is also a source of oxidative damage in pathological states (Martin et al., 2005; Bayir et al., 2007). However, in this model, NO appears to play its primary role as a signaling molecule in both healthy and diseased NMJ. Localized targeting of nNOS in the NMJ may be a reasonable therapeutic strategy to improve synaptic transmission in disorders of cholinergic excess.

The role of miRNA in synapse development and function is well established (Manakov et al., 2009; Schratt, 2009; Smalheiser and Lugli, 2009; Impey et al., 2010). There is also a growing realization that miRNA plays a prominent role in neurological and muscular disease (Bicker and Schratt, 2008; Chen et al., 2009; Christensen and Schratt, 2009; Williams et al., 2009; Huang et al., 2011). However, until now, the pathways through which NO affects presynaptic function have not been shown to occur through changes in expression of presynaptic proteins via a miRNA mechanism. Yet to be determined is the mechanism by which changes in CGMP or other NO targets lead to changes in specific miRNA levels in the presynaptic motor neuron. The characterization of this cascade provides new insights into transsynaptic communication and provides a wide array of potential targets for therapeutic intervention.

\section{References}

Adler M, Sweeney RE, Hamilton TA, Lockridge O, Duysen EG, Purcell AL, Deshpande SS (2011) Role of acetylcholinesterase on the structure and function of cholinergic synapses: insights gained from studies on knockout mice. Cell Mol Neurobiol 31:909-920. CrossRef Medline

Aonuma H, Nagayama T, Takahata M (2000) Modulatory effects of nitric oxide on synaptic depression in the crayfish neuromuscular system. J Exp Biol 203:3595-3602. Medline

Archer S (1993) Measurement of nitric oxide in biological models. FASEB J 7:349-360. Medline 
Bak M, Silahtaroglu A, Møller M, Christensen M, Rath MF, Skryabin B, Tommerup N, Kauppinen S (2008) MicroRNA expression in the adult mouse central nervous system. RNA 14:432-444. CrossRef Medline

Bayir H, Kagan VE, Clark RS, Janesko-Feldman K, Rafikov R, Huang Z, Zhang X, Vagni V, Billiar TR, Kochanek PM (2007) Neuronal NOSmediated nitration and inactivation of manganese superoxide dismutase in brain after experimental and human brain injury. J Neurochem 101: 168-181. CrossRef Medline

Ben-Ari Y (2008) Epilepsies and neuronal plasticity: for better or for worse? Dialogues Clin Neurosci 10:17-27. Medline

Bicker S, Schratt G (2008) microRNAs: tiny regulators of synapse function in development and disease. J Cell Mol Med 12:1466-1476. CrossRef Medline

Bradshaw JM, Kubota Y, Meyer T, Schulman H (2003) An ultrasensitive $\mathrm{Ca} 2+/$ calmodulin-dependent protein kinase II-protein phosphatase 1 switch facilitates specificity in postsynaptic calcium signaling. Proc Natl Acad Sci U S A 100:10512-10517. CrossRef Medline

Chen F, Qian L, Yang ZH, Huang Y, Ngo ST, Ruan NJ, Wang J, Schneider C, Noakes PG, Ding YQ, Mei L, Luo ZG (2007) Rapsyn interaction with calpain stabilizes AChR clusters at the neuromuscular junction. Neuron 55:247-260. CrossRef Medline

Chen JF, Mandel EM, Thomson JM, Wu Q, Callis TE, Hammond SM, Conlon FL, Wang DZ (2006) The role of microRNA-1 and microRNA-133 in skeletal muscle proliferation and differentiation. Nat Genet 38:228-233. CrossRef Medline

Chen JF, Callis TE, Wang DZ (2009) MicroRNAs and muscle disorders. J Cell Sci 122:13-20. CrossRef Medline

Christensen M, Schratt GM (2009) MicroRNA involvement in developmental and functional aspects of the nervous system and in neurological diseases. Neurosci Lett 466:55-62. CrossRef Medline

Cohen JE, Lee PR, Chen S, Li W, Fields RD (2011) MicroRNA regulation of homeostatic synaptic plasticity. Proc Natl Acad Sci U S A 108:11650-11655. CrossRef Medline

Denning L, Anderson JA, Davis R, Gregg JP, Kuzdenyi J, Maselli RA (2007) High throughput genetic analysis of congenital myasthenic syndromes using resequencing microarrays. PloS One 2:e918. CrossRef Medline

Engel AG, Lambert EH, Gomez MR (1977) A new myasthenic syndrome with end-plate acetylcholinesterase deficiency, small nerve terminals, and reduced acetylcholine release. Ann Neurol 1:315-330. CrossRef Medline

Engel AG, Lambert EH, Mulder DM, Torres CF, Sahashi K, Bertorini TE, Whitaker JN (1982) A newly recognized congenital myasthenic syndrome attributed to a prolonged open time of the acetylcholine-induced ion channel. Ann Neurol 11:553-569. CrossRef Medline

Engel AG, Ohno K, Milone M, Wang HL, Nakano S, Bouzat C, Pruitt JN 2nd, Hutchinson DO, Brengman JM, Bren N, Sieb JP, Sine SM (1996) New mutations in acetylcholine receptor subunit genes reveal heterogeneity in the slow-channel congenital myasthenic syndrome. Hum Mol Genet 5:1217-1227. CrossRef Medline

Engel AG, Shen XM, Selcen D, Sine SM (2010) What have we learned from the congenital myasthenic syndromes. J Mol Neurosci 40:143-153. CrossRef Medline

Etherington SJ, Everett AW (2004) Postsynaptic production of nitric oxide implicated in long-term depression at the mature amphibian (Bufo marinus) neuromuscular junction. J Physiol 559:507-517. CrossRef Medline

Evans GJ, Cousin MA (2007) Activity-dependent control of slow synaptic vesicle endocytosis by cyclin-dependent kinase 5. J Neurosci 27:401-411. CrossRef Medline

Fu AK, Ip FC, Fu WY, Cheung J, Wang JH, Yung WH, Ip NY (2005) Aberrant motor axon projection, acetylcholine receptor clustering, and neurotransmission in cyclin-dependent kinase 5 null mice. Proc Natl Acad Sci U S A 102:15224-15229. CrossRef Medline

Fu WY, Chen Y, Sahin M, Zhao XS, Shi L, Bikoff JB, Lai KO, Yung WH, Fu AK, Greenberg ME, Ip NY (2007) Cdk5 regulates EphA4-mediated dendritic spine retraction through an ephexin1-dependent mechanism. Nat Neurosci 10:67-76. CrossRef Medline

Gomez CM, Maselli R, Gammack J, Lasalde J, Tamamizu S, Cornblath DR, Lehar M, McNamee M, Kuncl RW (1996) A beta-subunit mutation in the acetylcholine receptor channel gate causes severe slow-channel syndrome. Ann Neurol 39:712-723. CrossRef Medline

Gomez CM, Maselli R, Gundeck JE, Chao M, Day JW, Tamamizu S, Lasalde JA, McNamee M, Wollmann RL (1997) Slow-channel transgenic mice: a model of postsynaptic organellar degeneration at the neuromuscular junction. J Neurosci 17:4170-4179. Medline

Gomez CM, Maselli RA, Vohra BP, Navedo M, Stiles JR, Charnet P, Schott K, Rojas L, Keesey J, Verity A, Wollmann RW, Lasalde-Dominicci J (2002) Novel delta subunit mutation in slow-channel syndrome causes severe weakness by novel mechanisms. Ann Neurol 51:102-112. CrossRef Medline

Graves AR, Lewin KA, A Lindgren C (2004) Nitric oxide, cAMP and the biphasic muscarinic modulation of ACh release at the lizard neuromuscular junction. J Physiol 559:423-432. CrossRef Medline

Greco SJ, Rameshwar P (2007) MicroRNAs regulate synthesis of the neurotransmitter substance $P$ in human mesenchymal stem cell-derived neuronal cells. Proc Natl Acad Sci U S A 104:15484-15489. CrossRef Medline

Griffiths-Jones S, Grocock RJ, van Dongen S, Bateman A, Enright AJ (2006) miRBase: microRNA sequences, targets and gene nomenclature. Nucl Acids Res 34:D140-144. CrossRef Medline

Groshong JS, Spencer MJ, Bhattacharyya BJ, Kudryashova E, Vohra BP, Zayas R, Wollmann RL, Miller RJ, Gomez CM (2007) Calpain activation impairs neuromuscular transmission in a mouse model of the slow-channel myasthenic syndrome. J Clin Invest 117:2903-2912. CrossRef Medline

Grozdanovic Z, Nakos G, Christova T, Nikolova Z, Mayer B, Gossrau R (1995) Demonstration of nitric oxide synthase (NOS) in marmosets by NADPH diaphorase (NADPH-d) histochemistry and NOS immunoreactivity. Acta Histochem 97:321-331. CrossRef Medline

Hawasli AH, Benavides DR, Nguyen C, Kansy JW, Hayashi K, Chambon P, Greengard P, Powell CM, Cooper DC, Bibb JA (2007) Cyclindependent kinase 5 governs learning and synaptic plasticity via control of NMDAR degradation. Nat Neurosci 10:880-886. CrossRef Medline

Hayashi Y, Nishio M, Naito Y, Yokokura H, Nimura Y, Hidaka H, Watanabe Y (1999) Regulation of neuronal nitric-oxide synthase by calmodulin kinases. J Biol Chem 274:20597-20602. CrossRef Medline

Hirasawa M, Ohshima T, Takahashi S, Longenecker G, Honjo Y, Veeranna, Pant HC, Mikoshiba K, Brady RO, Kulkarni AB (2004) Perinatal abrogation of Cdk5 expression in brain results in neuronal migration defects. Proc Natl Acad Sci U S A 101:6249-6254. CrossRef Medline

Huang ZP, Neppl RL Jr, Wang DZ (2011) Application of microRNA in cardiac and skeletal muscle disease gene therapy. Methods Mol Biol 709: 197-210. CrossRef Medline

Ikeda K, Iwasaki Y, Kinoshita M (1998) Neuronal nitric oxide synthase inhibitor, 7-nitroindazole, delays motor dysfunction and spinal motoneuron degeneration in the wobbler mouse. J Neurol Sci 160:9-15. CrossRef Medline

Impey S, Davare M, Lasiek A, Fortin D, Ando H, Varlamova O, Obrietan K, Soderling TR, Goodman RH, Wayman GA (2010) An activity-induced microRNA controls dendritic spine formation by regulating Rac1-PAK signaling. Mol Cell Neurosci 43:146-156. CrossRef Medline

Jánossy J, Ubezio P, Apáti A, Magócsi M, Tompa P, Friedrich P (2004) Calpain as a multi-site regulator of cell cycle. Biochem Pharmacol 67:15131521. CrossRef Medline

Janz R, Goda Y, Geppert M, Missler M, Südhof TC (1999) SV2A and SV2B function as redundant $\mathrm{Ca}^{2+}$ regulators in neurotransmitter release. Neuron 24:1003-1016. CrossRef Medline

Kim HK, Lee YS, Sivaprasad U, Malhotra A, Dutta A (2006) Muscle-specific microRNA miR-206 promotes muscle differentiation. J Cell Biol 174: 677-687. CrossRef Medline

Koelle GB, Friedenwald JA (1949) A histochemical method for localizing cholinesterase activity. Proc Soc Exp Biol Med 70:617-622. Medline

Kozomara A, Griffiths-Jones S (2011) miRBase: integrating microRNA annotation and deep-sequencing data. Nucleic Acids Res 39:D152-157. CrossRef Medline

Lee MS, Kwon YT, Li M, Peng J, Friedlander RM, Tsai LH (2000) Neurotoxicity induces cleavage of p35 to p25 by calpain. Nature 405:360-364. CrossRef Medline

Lindgren CA, Laird MV (1994) Nitroprusside inhibits neurotransmitter release at the frog neuromuscular junction. Neuroreport 5:2205-2208. CrossRef Medline

Manakov SA, Grant SG, Enright AJ (2009) Reciprocal regulation of microRNA and mRNA profiles in neuronal development and synapse formation. BMC Genomics 10:419. CrossRef Medline

Martin LJ, Chen K, Liu Z (2005) Adult motor neuron apoptosis is mediated by nitric oxide and Fas death receptor linked by DNA damage and p53 activation. J Neurosci 25:6449-6459. CrossRef Medline 
Martinez-Pena y Valenzuela I, Mouslim C, Akaaboune M (2010) Calcium/ calmodulin kinase II-dependent acetylcholine receptor cycling at the mammalian neuromuscular junction in vivo. J Neurosci 30:12455-12465. CrossRef Medline

Matteoli M, Takei K, Cameron R, Hurlbut P, Johnston PA, Südhof TC, Jahn R, De Camilli P (1991) Association of Rab3A with synaptic vesicles at late stages of the secretory pathway. J Cell Biol 115:625-633. CrossRef Medline

Mihaylova V, Müller JS, Vilchez JJ, Salih MA, Kabiraj MM, D’Amico A, Bertini E, Wölfle J, Schreiner F, Kurlemann G, Rasic VM, Siskova D, Colomer J, Herczegfalvi A, Fabriciova K, Weschke B, Scola R, Hoellen F, Schara U, Abicht A, Lochmüller H (2008) Clinical and molecular genetic findings in COLQ-mutant congenital myasthenic syndromes. Brain 131:747-759. CrossRef Medline

Nguyen C, Bibb JA (2003) Cdk5 and the mystery of synaptic vesicle endocytosis. J Cell Biol 163:697-699. CrossRef Medline

Nickels TJ, Reed GW, Drummond JT, Blevins DE, Lutz MC, Wilson DF (2007) Does nitric oxide modulate transmitter release at the mammalian neuromuscular junction? Clin Exp Pharmacol Physiol 34:318-326. CrossRef Medline

Nielsen AF, Gloggnitzer J, Martinez J (2009) MicroRNAs cross the line: the battle for mRNA stability enters the coding sequence. Mol Cell 35:139140. CrossRef Medline

Nishimura N, Goji J, Nakamura H, Orita S, Takai Y, Sano K (1995) Cloning of a brain-type isoform of human Rab GDI and its expression in human neuroblastoma cell lines and tumor specimens. Cancer Res 55:54455450. Medline

Ohno K, Brengman J, Tsujino A, Engel AG (1998) Human endplate acetylcholinesterase deficiency caused by mutations in the collagen-like tail subunit (ColQ) of the asymmetric enzyme. Proc Natl Acad Sci U S A 95:9654-9659. CrossRef Medline

Palop JJ, Mucke L (2010) Amyloid-beta-induced neuronal dysfunction in Alzheimer's disease: from synapses toward neural networks. Nat Neurosci 13:812-818. CrossRef Medline

Peltier HJ, Latham GJ (2008) Normalization of microRNA expression levels in quantitative RT-PCR assays: identification of suitable reference RNA targets in normal and cancerous human solid tissues. RNA 14:844-852. CrossRef Medline

Perrin BJ, Amann KJ, Huttenlocher A (2006) Proteolysis of cortactin by calpain regulates membrane protrusion during cell migration. Mol Biol Cell 17:239-250. CrossRef Medline

Poore CP, Sundaram JR, Pareek TK, Fu A, Amin N, Mohamed NE, Zheng YL, Goh AX, Lai MK, Ip NY, Pant HC, Kesavapany S (2010) Cdk5-mediated phosphorylation of delta-catenin regulates its localization and GluR2mediated synaptic activity. J Neurosci 30:8457-8467. CrossRef Medline

Quartarone A, Pisani A (2011) Abnormal plasticity in dystonia: Disruption of synaptic homeostasis. Neurobiol Dis 42:162-170. CrossRef Medline

Rameau GA, Tukey DS, Garcin-Hosfield ED, Titcombe RF, Misra C, Khatri L,
Getzoff ED, Ziff EB (2007) Biphasic coupling of neuronal nitric oxide synthase phosphorylation to the NMDA receptor regulates AMPA receptor trafficking and neuronal cell death. J Neurosci 27:3445-3455. CrossRef Medline

Roberts DV, Thesleff S (1969) Acetylcholine release from motor-nerve endings in rats treated with neostigmine. Eur J Pharmacol 6:281-285. CrossRef Medline

Robles E, Huttenlocher A, Gomez TM (2003) Filopodial calcium transients regulate growth cone motility and guidance through local activation of calpain. Neuron 38:597-609. CrossRef Medline

Schratt G (2009) microRNAs at the synapse. Nat Rev Neurosci 10:842-849. CrossRef Medline

Shapira YA, Sadeh ME, Bergtraum MP, Tsujino A, Ohno K, Shen XM, Brengman J, Edwardson S, Matoth I, Engel AG (2002) Three novel COLQ mutations and variation of phenotypic expressivity due to G240X. Neurology 58:603-609. CrossRef Medline

Smalheiser NR, Lugli G (2009) microRNA regulation of synaptic plasticity. Neuromolecular Med 11:133-140. CrossRef Medline

Smith PD, Mount MP, Shree R, Callaghan S, Slack RS, Anisman H, Vincent I, Wang X, Mao Z, Park DS (2006) Calpain-regulated p35/cdk5 plays a central role in dopaminergic neuron death through modulation of the transcription factor myocyte enhancer factor 2. J Neurosci 26:440-447. CrossRef Medline

Strickland ER, Hook MA, Balaraman S, Huie JR, Grau JW, Miranda RC (2011) MicroRNA dysregulation following spinal cord contusion: implications for neural plasticity and repair. Neuroscience 186:146-160. CrossRef Medline

Tiedt TN, Albuquerque EX, Hudson CS, Rash JE (1978) Neostigmineinduced alterations at the mammalian neuromuscular junction. I. Muscle contraction and electrophysiology. J Pharmacol Exp Ther 205: 326-339. Medline

Wang T, Xie Z, Lu B (1995) Nitric oxide mediates activity-dependent synaptic suppression at developing neuromuscular synapses. Nature 374:262-266. CrossRef Medline

Williams AH, Liu N, van Rooij E, Olson EN (2009) MicroRNA control of muscle development and disease. Curr Opin Cell Biol 21:461-469. CrossRef Medline

Yu B, Zhou S, Wang Y, Ding G, Ding F, Gu X (2011) Profile of microRNAs following rat sciatic nerve injury by deep sequencing: implication for mechanisms of nerve regeneration. PLoS One 6:e24612. CrossRef Medline

Zadran S, Bi X, Baudry M (2010) Regulation of calpain-2 in neurons: implications for synaptic plasticity. Mol Neurobiol 42:143-150. CrossRef Medline

Zhu H, Bhattacharyya BJ, Lin H, Gomez CM (2011) Skeletal muscle IP3R1 receptors amplify physiological and pathological synaptic calcium signals. J Neurosci 31:15269-15283. CrossRef Medline 